\title{
Pattern-Triggered Immunity Alters the Transcriptional Regulation of Virulence-Associated Genes and Induces the Sulfur Starvation Response in Pseudomonas syringae pv. tomato DC3000
}

\author{
Amelia H. Lovelace, ${ }^{1}$ Amy Smith, ${ }^{1}$ and Brian H. Kvitko ${ }^{1,2,+}$ \\ ${ }^{1}$ Department of Plant Pathology, University of Georgia, Athens, GA, U.S.A.; and ${ }^{2}$ The Plant Center, University of Georgia \\ Accepted 9 February 2018.
}

\begin{abstract}
Pattern-triggered immunity (PTI) can confer broad defense against diverse microbes and pathogens with disparate lifestyles through the detection of microbial extracellular signatures by surface-exposed pattern recognition receptors. However, unlike recognition of pathogen effectors by cytosolic resistance proteins, PTI is typically not associated with a hostcell programmed cell death response. Although host PTI signaling has been extensively studied, the mechanisms by which it restricts microbial colonization are poorly understood. We sought to gain insight into the mechanisms of PTI action by using bacterial transcriptomics analysis during exposure to PTI. Here, we describe a method for bacterial cell extraction from inoculated leaves that was used to analyze a time course of genome-wide transcriptional responses in the pathogen Pseudomonas syringae pv. tomato $\mathrm{DC} 3000$ during early naïve host infection and exposure to pre-induced PTI in Arabidopsis thaliana. Our analysis revealed early transcriptional regulation of important bacterial metabolic processes and host interaction pathways. We observed peak induction of $P$. syringae virulence genes at $3 \mathrm{~h}$ postinoculation and that exposure to PTI was associated with significant reductions in the expression of virulence genes. We also observed the induction of $P$. syringae sulfur starvation response genes such as sulfate and sulfonate importers only during exposure to PTI.
\end{abstract}

Plants encode an innate immune system organized around two major branches, pattern-triggered immunity (PTI) and effector-triggered immunity (ETI). Both use specific immune receptors to detect invading microbes. Cytosolic resistance (R) proteins recognize specific pathogen-secreted virulence effectors in a direct or indirect manner. Upon detection of a cognate effector, ETI is activated (van der Hoorn and Kamoun 2008). ETI typically induces a host programmed cell death

${ }^{\dagger}$ Corresponding author: Brian H. Kvitko; E-mail: bkvitko@uga.edu

Funding: Funding was provided by the United States National Institute of Food and Agriculture HATCH Project GEO00791 and the State of Georgia to Brian H. Kvitko.

Illumina sequencing data were deposited in the Gene Expression Omnibus under accession number GSE110100.

*The $\boldsymbol{e}$-Xtra logo stands for "electronic extra" and indicates that five supplementary figures and four supplementary datasets are published online.

(c) 2018 The American Phytopathological Society response known as the hypersensitive response (HR). ETI is effective against hemibiotrophic and biotrophic pathogens that require living plant cells to proliferate (Coll et al. 2011; Glazebrook 2005). Conversley, PTI confers broad defense against pathogens with diverse lifestyles, typically in the absence of a HR (Jones and Dangl 2006). To activate PTI, plants recognize broadly conserved microbe- or pathogen-associated molecular patterns (MAMPs or PAMPs) through surface-displayed pattern recognition receptors (PRRs). PRRs have been characterized that recognize MAMPs or PAMPs, such as peptidoglycan, lipopolysaccharides, and flagellin in bacteria and chitin in fungi (Böhm et al. 2014; Macho and Zipfel 2014). Upon recognition of MAMPs or PAMPs by cognate PRRs, the plant activates a signaling cascade resulting in the transcriptional activation of a network of immune responses (Buscaill and Rivas 2014). The deployment of plant disease $R$ genes for ETI-based immunity has been the primary method for disease control against crop pathogens. However, ETI based on single, dominant $R$ genes is often not durable in the face of rapid pathogen evolution (Fukuoka et al. 2015; McDowell and Woffenden 2003). The interfamily transfer of PRRs using transgenic approaches has been used to enhance resistance to whole classes of plant pathogens through their capacity to recognize new classes of MAMPs and PAMPs (Boutrot and Zipfel 2017). Although the molecular details of PRR MAMP or PAMP recognition and the downstream signaling cascade have been extensively studied, a mechanistic understanding of how PTI-associated outputs directly restrict the proliferation of microbes is lacking. Enhanced mechanistic insights into the mechanisms of PTI action could reveal new targets for re-engineering plant immune defense networks. Although most microbes can activate PTI through MAMP or PAMP presentation, many successful pathogens deploy virulence factors to actively counter PTI. Pathogens secrete virulence effectors, such as proteins and low molecular weight compounds that target host susceptibility factors (Macho and Zipfel 2015). Effectors play multiple roles in creating a state permissive to pathogen proliferation. Individual effectors have been shown to reprogram host metabolism to provide nutrition for pathogens (Chen 2010), enhance water soaking of the apoplast (Xin et al. 2016), and interfere with PTI and ETI signaling. These effector-driven processes collectively contribute to host susceptibility and the pathogen's capacity to colonize the host (Guo et al. 2009; Xin and He 2013). The bacterial pathogen $P$. syringae pv. tomato DC3000 (DC3000) has a well-studied repertoire of virulence factors allowing it to infect multiple plant hosts, including tomato and Arabidopsis thaliana. DC3000 uses a needle-like type III secretion system 
(T3SS) to deliver at least 30 virulence effector proteins, many with characterized roles in dampening PTI signaling, into the plant cytosol (Jin and He 2001; Li et al. 2002). DC3000 also produces the non-host specific phytotoxin coronatine, a structural mimic of the phytohormone jasmonyl-isoleucine, thus activating jasmonic acid signaling response genes (Bender et al. 1998). Coronatine is a multifunctional toxin able to induce the reopening of stomata to facilitate bacterial invasion as well as antagonize salicylic acid defense hormone pathways (Melotto et al. 2006; Zheng et al. 2012). During a typical infection, pathogen effector-mediated dampening of immunity is thought to outpace host PTI activation, allowing for adequate immune suppression to facilitate pathogen proliferation within the host. However, by pre-activating PTI prior to pathogen introduction, the host is able to suppress proliferation of normally compatible and competent pathogens. PTI can be pre-activated 12 to $24 \mathrm{~h}$ prior to bacterial inoculation by using a PAMP or MAMP pretreatment, such as bacterial flagellin or, more specifically, a 22-amino acid conserved epitope of bacterial flagellin (Zipfel et al. 2004), and tissue can be protected from infection for up to 2 days postinoculation (Crabill et al. 2010). When DC3000 is delivered into the PTI pre-induced apoplast, its ability to deliver effectors is restricted and it is unable to proliferate.(Crabill et al. 2010; Wei et al. 2013).

Once DC3000 enters the apoplast, it undergoes transcriptional reprograming to induce virulence genes, exopolysaccharides, and metabolic genes to adapt to its new environmental niche (Boch et al. 2002). In DC3000, most of the virulence genes are transcriptionally regulated by the ECF-family sigma factor HrpL. The regulation of DC3000 virulence genes has been primarily studied in vitro through the use of virulence factor inducing minimal media (Alfano and Collmer 1996). Direct study of $P$ syringae global transcriptional regulation in vivo has been limited. Yu et al. (2013) conducted a microarray transcriptomics analysis of $P$. syringae pv. syringae B728a recovered from the apoplast of bean leaves at 2 days postinoculation and the surface of bean leaves at 3 days postinoculation. Interestingly, they observed only limited differential expression of virulence genes between the two populations.

The use of RNASeq for transcriptome analysis of infecting foliar plant-pathogenic bacteria has been reported recently in the Dickeya dadantii-Arabidopsis necrotrophic pathosystem (Chapelle et al. 2015). In the current study, we sought to use global transcriptomics as measured by RNAseq to examine differential gene expression in DC3000 during naive host infection and exposure to pre-activated PTI. By using bacteria transcriptional responses as a readout, our goal was to uncover the mechanisms underlying PTI-mediated restriction of DC3000 growth.

\section{RESULTS}

\section{Physical separation facilitates recovery of bacterial RNA from inoculated leaf tissues.}

A protocol for the physical separation of bacteria from leaf tissue was developed to obtain sufficient amounts of stabilized bacterial RNA for RNAseq transcriptomics analysis. DC3000 suspensions were inoculated, using a needle-less syringe, into approximately 80 Arabidopsis leaves for each sampling timepoint (four fully expanded leaves on twenty 4- to 5-week-old Col-0 Arabidopsis plants). Samples of the starting inoculum were pelleted and were saved for RNA extraction as a time-0 baseline. At each sampling time, leaves were detached and were infiltrated, using vacuum pressure, with an RNAstabilizing buffer (De Wit et al. 2012). This stabilized the inplanta DC3000 transcriptome in its in-situ state and acted as a liquid carrier for physical separation. Bacteria were recovered from inoculated leaf tissue by low speed centrifugation in a manner similar to procedures used for the recovery of apoplastic wash fluid (Fig. 1) (O'Leary et al. 2014). The recovered bacteria were further concentrated and were separated from bulk wash fluid using a syringe filter unit, and the filters were stored at $-80^{\circ} \mathrm{C}$ until processing. Total RNA was purified from in-planta and starting inoculum samples using Trizol and the DirectZol miniprep kit with both on-column and offcolumn DNAse treatment. The concentration of bacterial RNA within each total RNA sample was estimated using reverse transcription-quantitative polymerase chain reaction (RT-qPCR) and $P$. syringae-specific $16 \mathrm{~S}$ ribosomal RNA (rRNA) primers from a subset of experimental samples (Smith et al. 2018). Using these estimates, a multiplex pooling scheme was developed to equalize the sequencing read depth for each sample (e.g., the starting inoculum library was combined at a 1:80 ratio with other sample libraries). Prior to sequencing library preparation, bacterial rRNA was depleted using the Illumina Ribo-Zero kit (Supplementary Fig. S1). Pooled samples were sequenced, across three full Illumina flow cells, using the NextSeq platform. The number of sequenced, non-rRNA reads mapped to the DC3000 genome ranged from six to 32 million, correlating to coverage of 74 to 365 (Table 1). Bacterial RNA represented 10 to $50 \%$ of the mapped sequenced reads from in-planta samples and 76 to $98 \%$ of the sequenced reads from the time-0 baseline starting inoculum (Fig. 2).

\section{Transcriptomic analysis of DC3000 during early Arabidopsis naïve infection and exposure to PTI.}

We compared the RNAseq transcriptome profiles of DC3000 exposed to pre-activated PTI and during naive host infection of A. thaliana leaves at 1,3 , and $5 \mathrm{~h}$ postinoculation (hpi) with the DC3000 transcriptome profile in time-0 baseline starting inoculum. PTI was induced in leaves using a syringe infiltration of $1 \mu \mathrm{M}$ flg22 in $0.1 \%$ dimethyl sulfoxide (DMSO) $20 \mathrm{~h}$ prior to bacterial inoculation whereas naïve plants were infiltrated with a $0.1 \%$ DMSO mock treatment. Samples were collected independently at each timepoint, with triplicate experimental repeats. PTI pre-activated Arabidopsis leaves were observed to be protected against the high concentration of DC3000 (approximately $1 \times 10^{9} \mathrm{CFU} / \mathrm{ml}$ ) required to recover sufficient RNA for transcriptomics analysis. The amount of bacteria recovered from PTI pre-activated leaf tissue was significantly less than that recovered from naive leaf tissue by 5 and $12 \mathrm{hpi}$ and resulted in reduced infection-associated cell death compared with naïve leaf tissue by 24 hpi (Supplementary Fig. S2). A total of 5,698 differentially expressed genes (DEGs) were identified between all samples (Supplementary Datasets S1 and S2). DEGs were determined both by comparison of in-planta DC3000 samples to the starting inoculum and by comparison between paired timepoints for DC3000 exposed to PTI and during naïve host infection. Principal components analysis of the $\log _{2}$-transformed gene counts for all DEGs for all DC3000 samples revealed a strong shift in the bacterial transcriptome profile at $1 \mathrm{hpi}$ compared with the profile of the time- 0 baseline starting inoculum. DC3000 transcriptome profiles exposed to PTI and during naïve host infection clustered together at 1 hpi. By 3 hpi, the bacterial transcriptome profile of DC3000 extracted during naive host infection experienced an additional transcriptional shift and this pattern continued at 5 hpi. In contrast, the bacterial transcriptome profiles of DC3000 exposed to PTI at 3 and 5 hpi continued to cluster with bacteria exposed to PTI at 1 hpi (Fig. 3).

\section{Pathway analysis reveals}

unique transcriptional signatures associated with early naïve infection and exposure to PTI.

Kyoto Encyclopedia of Genes and Genomes (KEGG) pathway analysis on DEGs was conducted to determine which DC3000 pathways were upregulated or downregulated during naïve host infection and exposure to PTI. DEGs were determined both by comparison of in-planta samples with the DC3000 
starting inoculum and by comparison between paired timepoints for DC3000 exposed to PTI and during naive host infection. Of the total 79 KEGG pathways annotated within the DC3000 genome, 24 were found to be significantly upregulated or downregulated between the two treatments (Fig. 4; Supplementary Dataset S3). DC3000 had similar overall patterns in pathway expression during naïve host infection and exposure to PTI as compared with the starting inoculum. For example, motilityassociated pathways, such as flagellar assembly, bacterial chemotaxis, and many two-component regulatory systems, were significantly downregulated in DC3000 in-planta samples at most timepoints relative to the starting inoculum (Fig. 4, naive vs. inoculum and PTI vs. inoculum). Although the annotated
KEGG two-component system genes comprise a variety of biological functions, most of the genes that were significantly downregulated are involved in motility and chemotaxis (Supplementary Dataset S4). Pathways for replication and virulence were significantly upregulated during naïe host infection and exposure to PTI relative to the starting inoculum. The significantly upregulated pathways involved in replication include DNA metabolism (purine/pyrimidine), transfer (t)RNA biosynthesis, and ribosome synthesis (Fig. 4). Secondary metabolites were also significantly upregulated during naive host infection and exposure to PTI relative to the starting inoculum. These secondary metabolite genes are associated with amino acid, carbohydrate, and lipid metabolism. Induction of the T3SS,
A

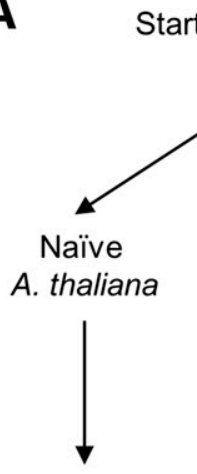

Harvest leaves

(1 hpi)<smiles>CI</smiles>

Harvest leaves

(3 hpi)<smiles>CO</smiles>

Harvest leaves

(5 hpi)
PTI-induced

A. thaliana

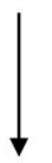

Harvest leaves

(1 hpi)

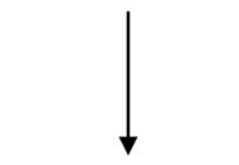

Harvest leaves

(3 hpi)

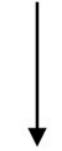

Harvest leaves (5 hpi)
B

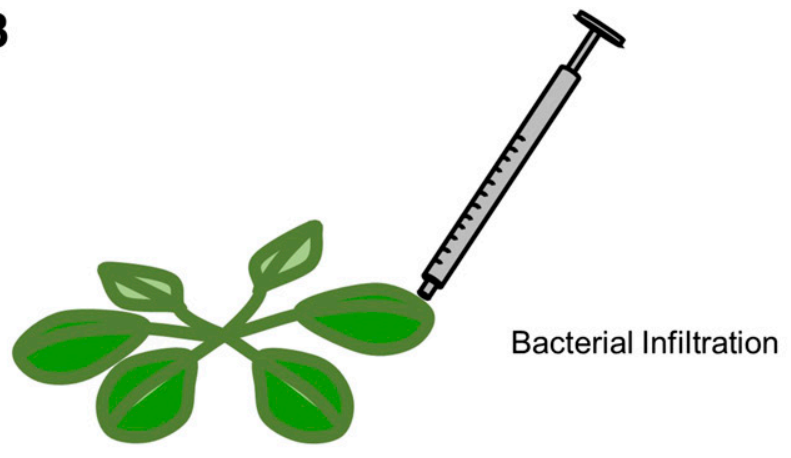

Harvest leaves 1, 3, and 5 hpi
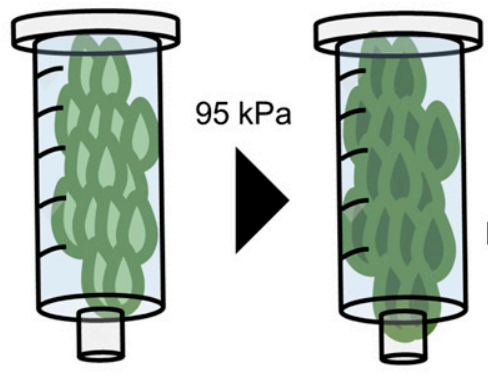

Vacuum Infiltration with RNA stabilizing buffer

Drain excess

RNA stabilizing buffer

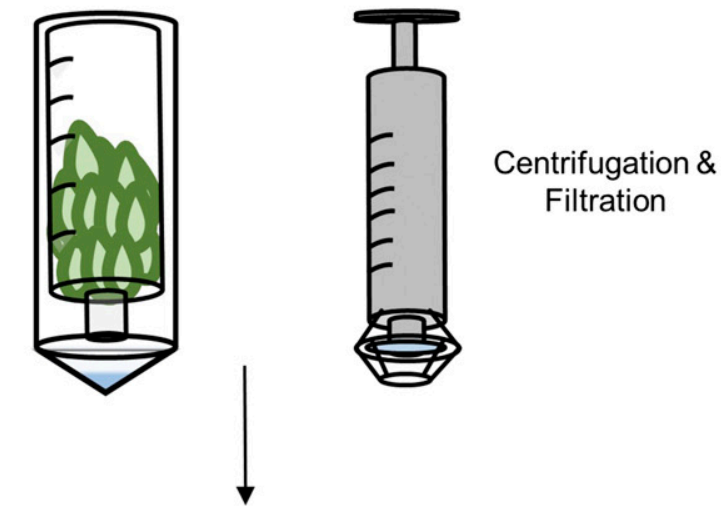

RNA extraction and Bacterial rRNA depletion

Fig. 1. Isolating Pseudomonas syringae pv. tomato DC3000 transcriptome in planta. A, Workflow for time-course sample collection and B, isolation and enrichment of bacterial RNA from inoculated Arabidopsis thaliana leaves. This method relies on physical separation of the bacteria from inoculated leaves. 
which plays an essential role in $P$. syringae pathogenicity, and its capacity to suppress plant immunity, comprised the majority of the upregulated KEGG bacterial secretion system pathway genes. The T3SS genes were significantly upregulated relative to the starting inoculum at all timepoints, both during naive host infection and during exposure to PTI (Fig. 4). Although the same

Table 1. Read depth and coverage for sequenced bacterial RNA samples ${ }^{\mathrm{a}}$

\begin{tabular}{llccc}
\hline Time & Condition & Replicate & Read depth & Coverage $^{\mathbf{c}}$ \\
\hline $1 \mathrm{hpi}$ & Nä̈ve & 1 & $3.07 \mathrm{E}+07$ & 352 \\
$1 \mathrm{hpi}$ & Naïve & 2 & $2.53 \mathrm{E}+07$ & 290 \\
$1 \mathrm{hpi}$ & Nä̈ve & 3 & $3.17 \mathrm{E}+07$ & 364 \\
$1 \mathrm{hpi}$ & PTI & 1 & $1.83 \mathrm{E}+07$ & 210 \\
$1 \mathrm{hpi}$ & PTI & 2 & $2.02 \mathrm{E}+07$ & 231 \\
$1 \mathrm{hpi}$ & PTI & 3 & $1.19 \mathrm{E}+07$ & 136 \\
$3 \mathrm{hpi}$ & Naïve & 1 & $1.52 \mathrm{E}+07$ & 174 \\
$3 \mathrm{hpi}$ & Nä̈ve & 2 & $1.66 \mathrm{E}+07$ & 191 \\
$3 \mathrm{hpi}$ & Nä̈ve & 3 & $1.17 \mathrm{E}+07$ & 135 \\
$3 \mathrm{hpi}$ & PTI & 1 & $1.83 \mathrm{E}+07$ & 209 \\
$3 \mathrm{hpi}$ & PTI & 2 & $6.42 \mathrm{E}+06$ & 74 \\
$3 \mathrm{hpi}$ & PTI & 3 & $1.89 \mathrm{E}+07$ & 217 \\
$5 \mathrm{hpi}$ & Nä̈ve & 1 & $2.07 \mathrm{E}+07$ & 237 \\
$5 \mathrm{hpi}$ & Nä̈ve & 2 & $7.37 \mathrm{E}+06$ & 85 \\
$5 \mathrm{hpi}$ & Nä̈ve & 3 & $2.23 \mathrm{E}+07$ & 256 \\
$5 \mathrm{hpi}$ & PTI & 1 & $9.37 \mathrm{E}+06$ & 107 \\
$5 \mathrm{hpi}$ & PTI & 2 & $1.09 \mathrm{E}+07$ & 125 \\
$5 \mathrm{hpi}$ & PTI & 3 & $2.25 \mathrm{E}+07$ & 258 \\
$0 \mathrm{hpi}$ & Inoculum & 1 & $1.23 \mathrm{E}+07$ & 141 \\
$0 \mathrm{hpi}$ & Inoculum & 2 & $8.03 \mathrm{E}+06$ & 92 \\
$0 \mathrm{hpi}$ & Inoculum & 3 & $1.01 \mathrm{E}+07$ & 116 \\
\hline
\end{tabular}

${ }^{\mathrm{a}} \mathrm{PTI}=$ pattern-triggered immunity hpi $=\mathrm{h}$ postinoculation .

b Read depth calculated as total non-rRNA reads mapped to the Pseudomonas syringae pv. tomato DC3000 genome (NC_004578.1, NC_004632.1, NC_004633.1) from EDGE-pro v.1.3.1 output.

${ }^{c}$ Coverage calculated as the product of read depth and read length divided by the total genome size, in which the read length is $75 \mathrm{bp}$ and the total genome size for $P$. syringae pv. tomato DC3000 is 6,538,260 bp. general trends in pathways were found in in-planta samples, the strength of these trends for bacterial samples during naive host infection and exposure to PTI differ significantly (Fig. 4, PTI versus naïve). For instance, despite both sets of in-planta samples exhibiting downregulation of motility-associated pathways compared with the starting inoculum, motility-associated pathways were observed as significantly upregulated in bacteria exposed to PTI, compared with those during naïve host infection (Fig. 4). Similarly, pathways associated with growth, including oxidative phosphorylation, citrate cycle, peptidoglycan biosynthesis, lipopolysaccharide biosynthesis, tRNA biosynthesis, amino acid biosynthesis, and, ribosomes, were significantly downregulated in bacteria exposed to PTI, compared with bacteria during naïve host infection (Fig. 4). Conversely, compared with bacteria during naive infection, DC3000 exposure to PTI was associated with the upregulation of branched chain amino acid degradation, ABC transporters, and sulfur metabolism. Sulfur metabolism represents the sole KEGG pathway that was significantly upregulated in bacteria exposed to PTI when compared either with the starting inoculum or bacteria during naive infection.

\section{Differential expression of oxidative and osmotic stress response genes during exposure to PTI in Arabidopsis.}

Pathways for polysaccharide synthesis, compatible solute synthesis, and quarternary ammonium compound transport were found to be part of the osmotic stress response regulon and antioxidant enzymes were found to be part of the oxidative stress response regulon in $P$. syringae pv. syringae $\mathrm{B} 728 \mathrm{a}$ ( $\mathrm{Yu}$ et al. 2013). Orthologous genes for these stress response genes were identified in DC3000 and their expression was analyzed in bacteria exposed to PTI relative to bacteria during naïve host infection. Genes involved in alginate synthesis were significantly downregulated in bacteria exposed to PTI relative to bacteria during naïve host infection at all timepoints (Supplementary Fig. 3A). Similarly, genes encoding quarternary ammonium compound ABC transporters were significantly downregulated in

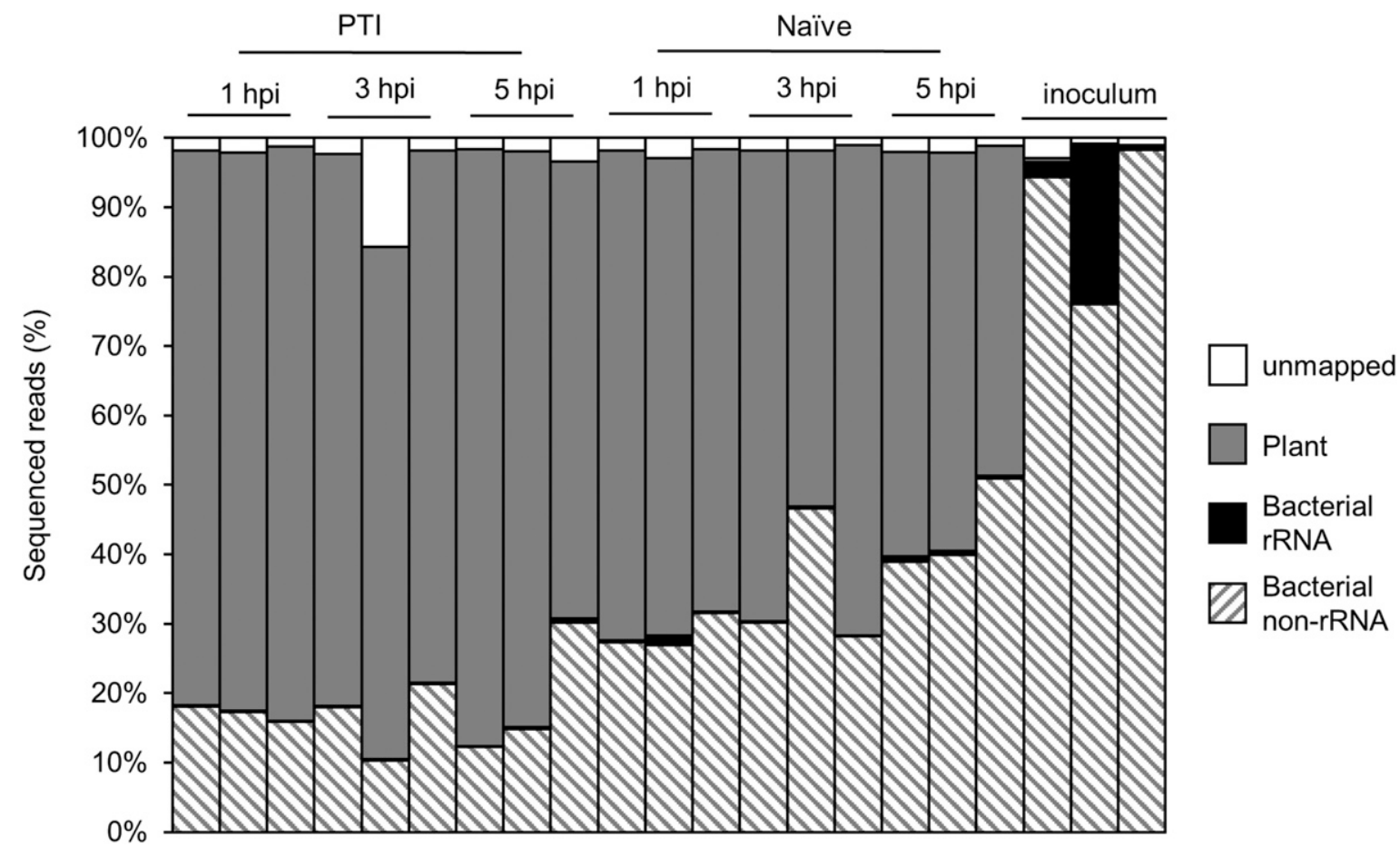

Fig. 2. Read distribution within Pseudomonas syringae pv. tomato DC3000 and host genome. The proportion of sequence reads mapped to P. syringae pv. tomato DC3000 genome including non-ribosomal RNA (non-rRNA) and rRNA, A. thaliana genome (Plant), and unmapped reads for all samples. Total RNA samples isolated from pattern-triggered immunity-induced (PTI) and naive (naïe) leaves inoculated with $P$. syringae pv. tomato DC3000 for 1 , 3 , and $5 \mathrm{~h}$ postinoculation (hpi) $(n=3)$. Inoculum RNA samples isolated from bacterial starting inoculum $($ optical density at $600 \mathrm{~nm}=0.8)(n=3)$. 
bacteria exposed to PTI relative to bacteria during naive host infection at 3 and 5 hpi. Genes involved in the synthesis of the compatible solute glycogen were significantly upregulated in bacteria exposed to PTI relative to bacteria during naïve infection at $5 \mathrm{hpi}$. Nine of the 18 antioxidant enzyme-encoding orthologous genes were significantly upregulated in bacteria exposed to PTI, relative to bacteria during naïve host infection, by $5 \mathrm{hpi}$.

\section{Regulation of DC3000 virulence genes during} early naïve infection and exposure to PTI in Arabidopsis.

The DC3000 tripartite pathogenicity island (T-PAI) encodes the T3SS structural proteins, the essential transcriptional regulators HrpR, HrpS, and the ECF-family sigma factor HrpL, some conserved T3SS effectors (T3E), and T3SS helper genes. T-PAI genes were significantly upregulated, in bacteria exposed to PTI and during naive host infection, for 1,3 , and $5 \mathrm{hpi}$, relative to the starting inoculum. However, in bacteria exposed to PTI, most T-PAI genes were induced less strongly than were observed in bacteria during naïve host infection (Fig. 5). Relative expression of T-PAI genes was the highest at $3 \mathrm{hpi}$ for both bacteria during naive host infection and when exposed to PTI. During naïve host infection, T-PAI gene expression decreased at 5 hpi. Conversely, during exposure to PTI, DC3000 T-PAI gene expression was largely unchanged between 3 and 5 hpi (Fig. 5). The ECF sigma factor HrpL, which regulates the expression of T3SS structural genes, T3E, and chaperones and T3E helpers through recognition of hrp box promoters, follows a gene-expression pattern consistent with that of the other PAI genes. It displayed significantly higher relative expression in DC3000 during naive host infection compared with bacteria exposed to PTI at 3 hpi (Supplementary Fig. S4). In contrast to $h r p L$, the upstream AAA-ATPase RpoN enhancers, $h r p R$ and hrpS, had significantly higher relative expression in DC3000 at 1 hpi during naïve host infection compared with bacteria exposed to PTI. However, this expression pattern was reversed at $5 \mathrm{hpi}$ (Fig. 5). The relative expression of the T-PAI gene PSPTO_1371, annotated as a bestrophin-family anion channel, was induced in planta but showed little change in expression over time and showed similar overall expression levels between in-planta treatments, with a slight increase in expression in bacteria exposed to PTI (Fig. 5). At 1 hpi in bacteria exposed to PTI, the T3E $a v r E 1$ and its chaperone $s c h E$ as well as the lytic transglycosylase helper $h r p H$ and the HrpL-repressing transcription factor $h r p V$ were not significantly differentially expressed relative to the starting inoculum.

T3Es and helper genes located outside of the PAI exhibited similar expression patterns to those of the T-PAI genes. Most genes had peak differential expression observed at $3 \mathrm{hpi}$, after which the relative expression decreased for bacteria during infection of naive tissue. In contrast, the expression level was largely maintained for bacteria exposed to PTI between 3 and 5 hpi (Fig. 6). In addition, most T3E and helper genes displayed higher levels of relative expression in bacteria during naive host infection than bacteria exposed to PTI (Fig. 6). Several effectors and chaperones thought to be part of the actively deployed DC3000 effector repertoire were observed to be nondifferentially induced at all timepoints in bacteria exposed to PTI. These noninduced effectors and chaperones include hopRl, hopV1, hopAA1-2, hopT1-1, hopK1, shcOl, hopBM1, and hopX1 (Fig. $6)$. In contrast, the chaperone $s h c S 1$ and the non-HrpL regulated T3E genes hopAH2-1 and hopAH2-2 were the only genes observed with higher relative expression levels in bacteria exposed to PTI than during naïve host infection at any timepoint (Fig. 6). Interestingly, the effector gene hopAH2-2 was only differentially expressed in bacteria exposed to PTI. Several effector genes, namely hopT2, hopO1-3, hopT1-2, hopO1-2, hopAI1, and hopAH1, that each lack evidence for HrpL-dependent expression in in-vitro analysis were here observed as noninduced relative to the starting inoculum, confirming previous observations summarized by Cunnac et al. (2009) (Fig. 6).

DC3000 genes for the synthesis of the phytohormone-mimicking toxin coronatine are encoded within the chromosome by two synthetic operons, $c f a$ and $c m a$, plus the singlet gene $c m a L$ found in effector cluster IX. The two-component regulators for the $c f a$ and cma operons $c o r S$, encoding a transmembrane histidine kinase, and $\operatorname{cor} R$, encoding a response regulator, are located adjacent to the $\mathrm{cma}$

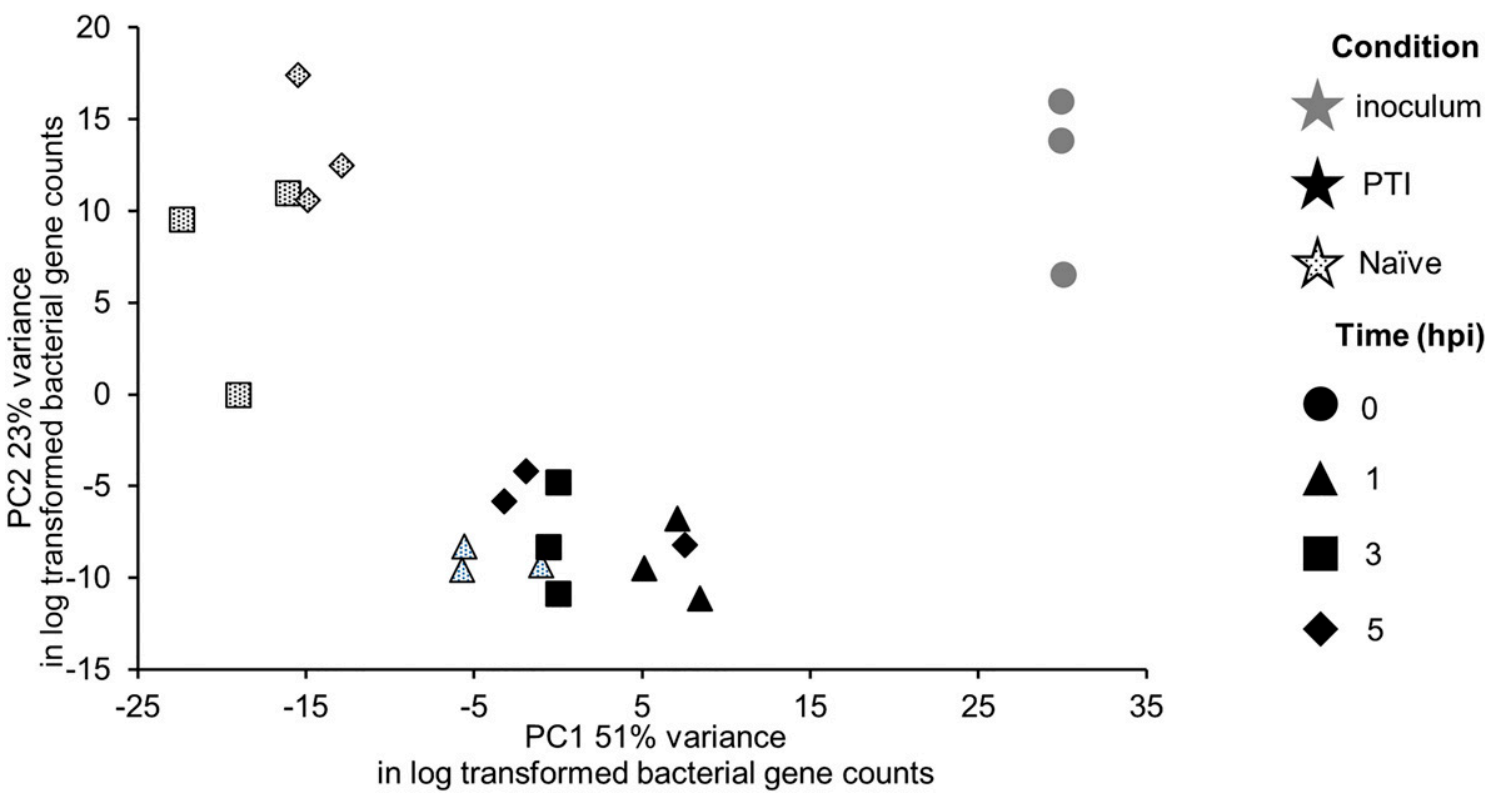

Fig. 3. Pseudomonas syringae pv. tomato DC3000 transcriptome profile in Arabidopsis thaliana tissue under various conditions and at different timepoints. Principal components analysis of the gene-expression profile, measured in log-transformed bacterial gene counts for all samples under all conditions and timepoints ( $n=3$ for each condition and time). Gene counts were transformed using the rlog function in DESeq2 v.1.14.1 R package. Bacterial gene counts from sequenced total RNA samples including starting inoculum (inoculum), inoculated pattern-triggered immunity-induced A. thaliana leaves (PTI), and inoculated naïve A. thaliana leaves (naïve). 
operon. In DC3000, corR is additionally HrpL regulated through cotranscription with the HrpL-regulated gene hopAQ1. At $1 \mathrm{hpi}$ during naivve host infection and exposure to PTI, DC3000 coronatine synthesis genes were either not significantly differentially expressed or significantly downregulated relative to the starting inoculum (Fig. 7). In contrast, at $1 \mathrm{hpi}$, the transcriptional regulators corR and corS as well as the HrpL-regulated gene hopAQ1 and the coronafacic acid synthetase gene $c f a l$ were significantly upregulated during naive host infection, but not during exposure to PTI (Fig. 7). During naive host infection, most coronatine synthesis genes had peak relative expression values at $5 \mathrm{hpi}$, while the regulatory genes $\operatorname{corR}$ and $\operatorname{cor} S$ as well as regulation-associated genes hopAQ1 and $\operatorname{cor} P$ showed peak relative expression at $3 \mathrm{hpi}$. The expression of coronatine synthesis and regulatory genes is consistently much lower in bacteria exposed to PTI at 3 and 5 hpi (Fig. 7).

\section{Sulfur importer genes are induced in DC3000 during early exposure to PTI in Arabidopsis.}

One pathway identified to be uniquely upregulated in bacteria exposed to PTI was sulfur metabolism. In fact, sulfur metabolism was significantly upregulated in bacteria exposed to PTI at all timepoints relative to the starting inoculum (Fig. 4).

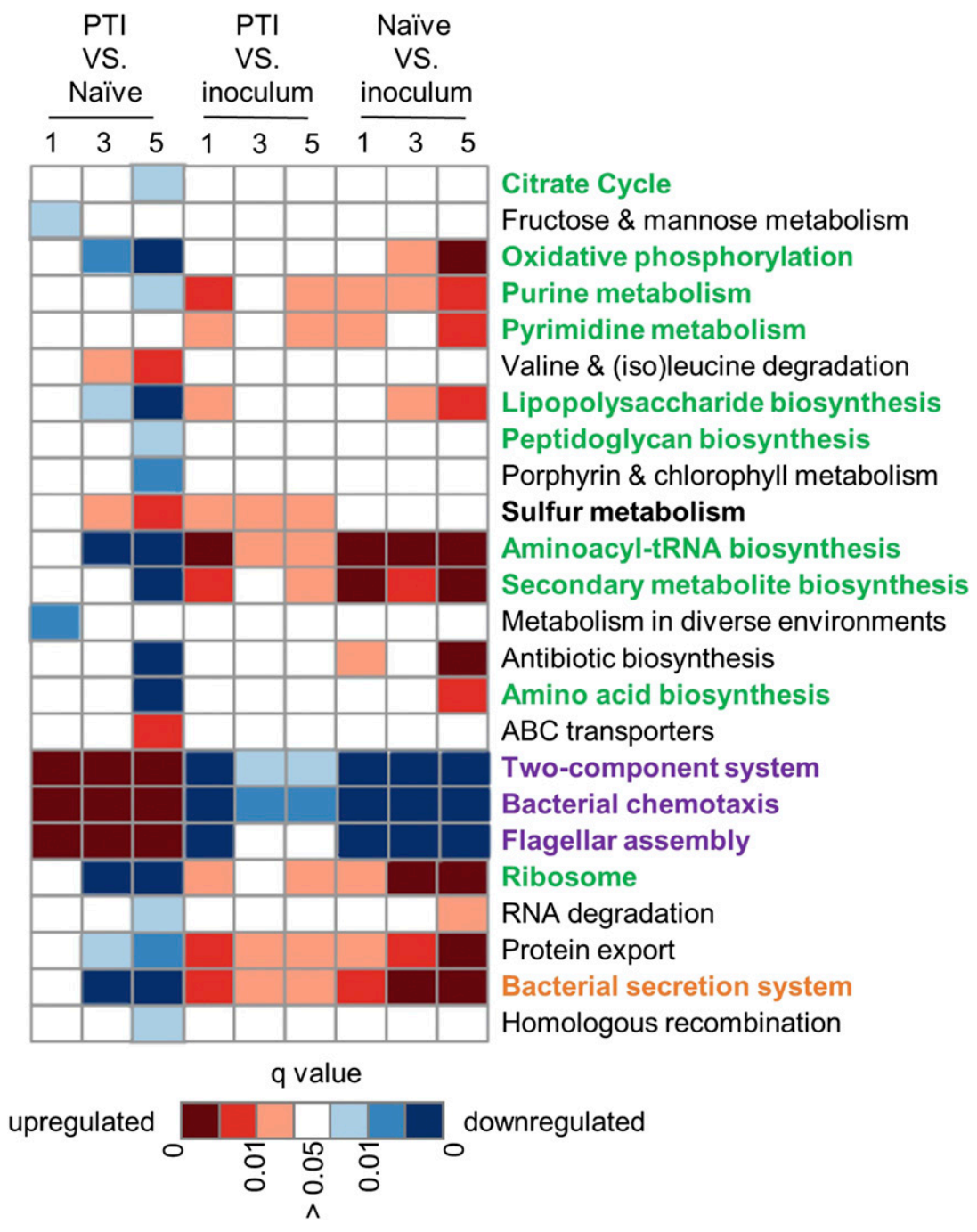

Fig. 4. Differentially expressed Pseudomonas syringae pv. tomato DC3000 KEGG (Kyoto Encyclopedia of Genes and Genomes) pathways for various comparisons and timepoints. Heat map of $q$ value for KEGG pathways representing the differentially expressed genes in different comparisons at 1,3 , and $5 \mathrm{~h}$ postinoculation (hpi). Differentially expressed P. syringae pv. tomato DC3000 pathways were identified using gauge function in gauge v.2.24.0 R package. White cells are not significantly differentially expressed $(q>0.05)$. Blue and red cells are significantly differentially downregulated and upregulated, respectively $(q<0.05)$; inoculum $=$ bacteria isolated from starting inoculum, PTI = bacteria isolated from pattern-triggered immunity-induced Arabidopsis thaliana leaves, Naïve = bacteria isolated from naïve A. thaliana leaves. Bold pathways represent pathways addressed in the text. Pathways colored in bold based on overall function with purple, green, orange, and black pathways associated with motility, replication, virulence, and sulfur metabolism, respectively.

Additionally, by 3 hpi, sulfur metabolism was significantly upregulated in bacteria exposed to PTI relative to bacteria during naive host infection (Fig. 4). Of the 41 genes annotated as involved in sulfur metabolism, 16 of the sulfur importer genes are significantly upregulated in bacteria exposed to PTI relative to bacteria during naive host infection at 5 hpi (Fig. 8). These importer genes encode $\mathrm{ABC}$ transporters for a variety of sulfur sources, including alkanesulfonates, taurine, and sulfate (Fig. 8). In addition to importers, monooxygenase genes associated with the catabolism of sulfonates and taurine were also significantly upregulated, especially in pathways involved in conversion of sulfonates to sulfite (Fig. 8). One ABC transporter system for the sulfur-containing amino acid methionine was also significantly upregulated by $5 \mathrm{hpi}$ in bacteria exposed to PTI; however, a (ransporter was significantly downregulated (Fig. 8). The annotated $\mathrm{ABC}$ transporter system for cysteine was not significantly differentially expressed. The differentially expressed or were significantly downregulated in bacteria exposed to PTI relative to bacteria during naive host infection (Fig. 8).

Citrate Cycle

Fructose \& mannose metabolism

Purine metabolism

Pyrimidine metabolism

Lipopolysaccharide biosynthesis

Peptidoglycan biosynthesis

Porphyrin \& chlorophyll metabolism

Secondary metabolite biosynthesis

environments

$A B C$ transporters

Flagellar assembly

Protein export

Bacterial secretion system

Homologous recombination

q value 
RT-qPCR analysis on select DC3000 genes during Arabidopsis infection and exposure to PTI supports RNASeq observations.

To ensure that our observations were neither artifacts of the high inoculum load nor the result of expression pattern biases in the recovered bacterial population versus the total bacterial population, the expression of key bacterial genes associated with major pathways altered by PTI exposure were monitiored in whole leaves inoculated at a lower infectious dose, using an RT-qPCR approach (Smith et al. 2018). For RT-qPCR, whole Arabidopsis leaves inoculated with $5 \times 10^{7}$ CFU of DC3000 per milliliter were collected, using the same treatments and timepoints as for RNAseq analysis. Leaves were flash-frozen in liquid nitrogen prior to total RNA extraction using Trizol and
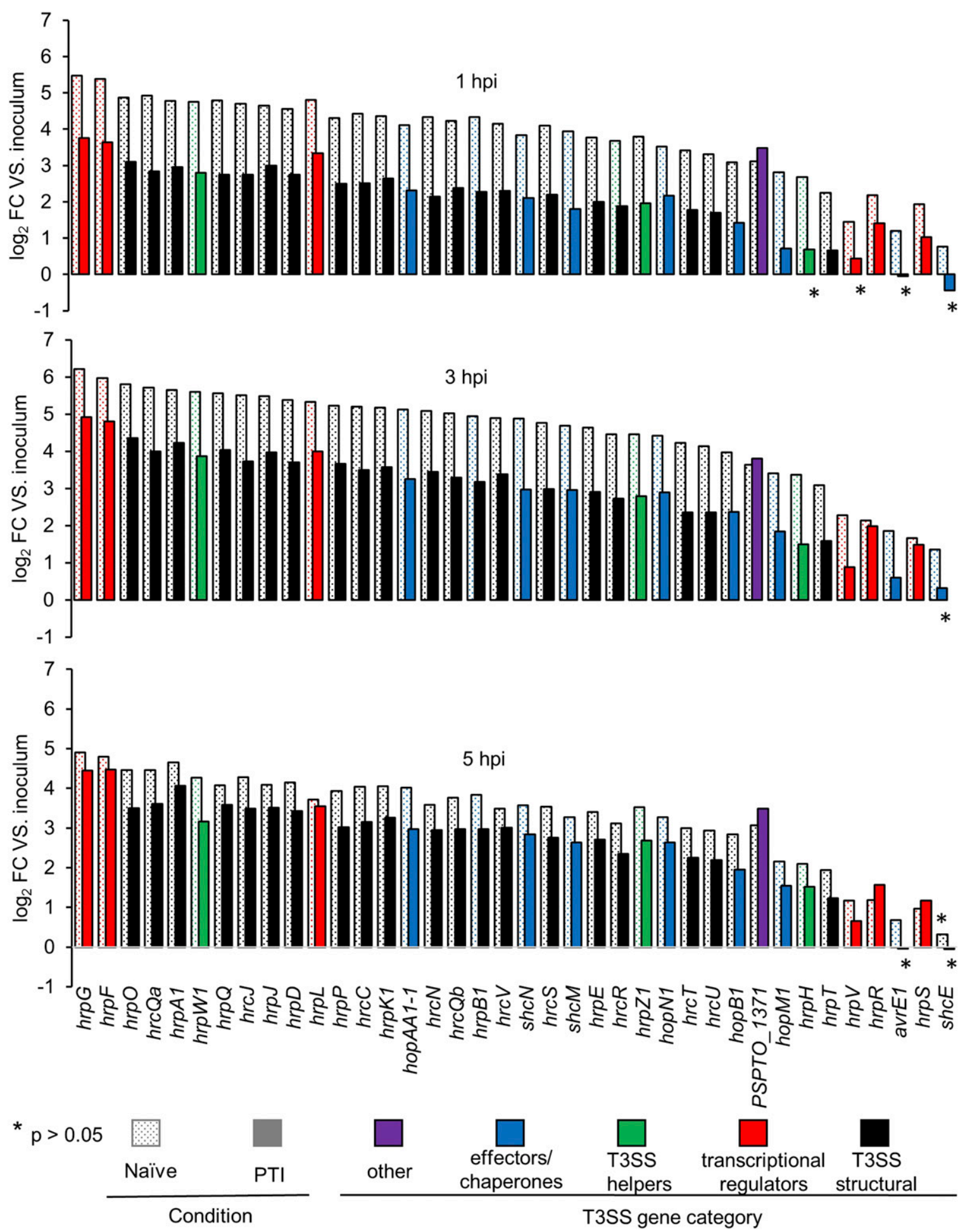

Fig. 5. Upregulation of Pseudomonas syringae pv. tomato DC3000 pathogenicity island (PAI) genes relative to the starting inoculum for varying timepoints. Differentially expressed bacterial genes found in the PAI of P. syringae pv. tomato DC3000 in in-planta samples under two conditions (pattern-triggered immunity [PTI] and naive) relative to the starting inoculum (inoculum) measured as $\log _{2}$ fold change in mean normalized gene counts. Differential expression was calculated using the DESeq function in the DESeq2 v.1.14.1 R package. Genes sorted by the naive $3 \mathrm{~h}$ postinoculation (hpi) sample. Asterisks indicate not significantly differentially expressed genes $(P>0.05)$ for naïve samples (above $x$ axis) and PTI samples (below $x$ axis). 
the DirectZol miniprep kit. The genes $c f l$ (coronafacic acid synthetase), $s b p$ (sulfate binding protein), PSPTO_5316 (the periplasmic binding protein for a sulfonate $\mathrm{ABC}$ transporter), hrpAl (the pilin of the T3SS), and fliC (flagellin) were selected as marker genes of coronatine production, sulfate and sulfonate uptake, T3SS, and flagella, respectively. Reference genes $r e c A$ and $o p r F$ were selected for the RT-qPCR analysis, as they were found to be the two most stable genes in our RNASeq dataset of the top three most stable reference genes (recA, oprF, and $r p o D$ ) previously validated by Smith et al. (2018). Stability was assessed by differential expression adjusted $P$ values between various treatments and timepoints, with genes with the greatest adjusted $P$ value under the most conditions selected as the most stable and less likely to be differentially expressed. Differential expression trends observed using RT-qPCR during PTI exposure relative to naive host infection exhibited very high positive correlation $(r>0.88)$ with those observed using RNAseq (Fig. 9). Expression of $c f l$ was repressed by PTI exposure, whereas fliC expression and sulfur-source importer genes were observed to be induced during PTI exposure relative to naïve host
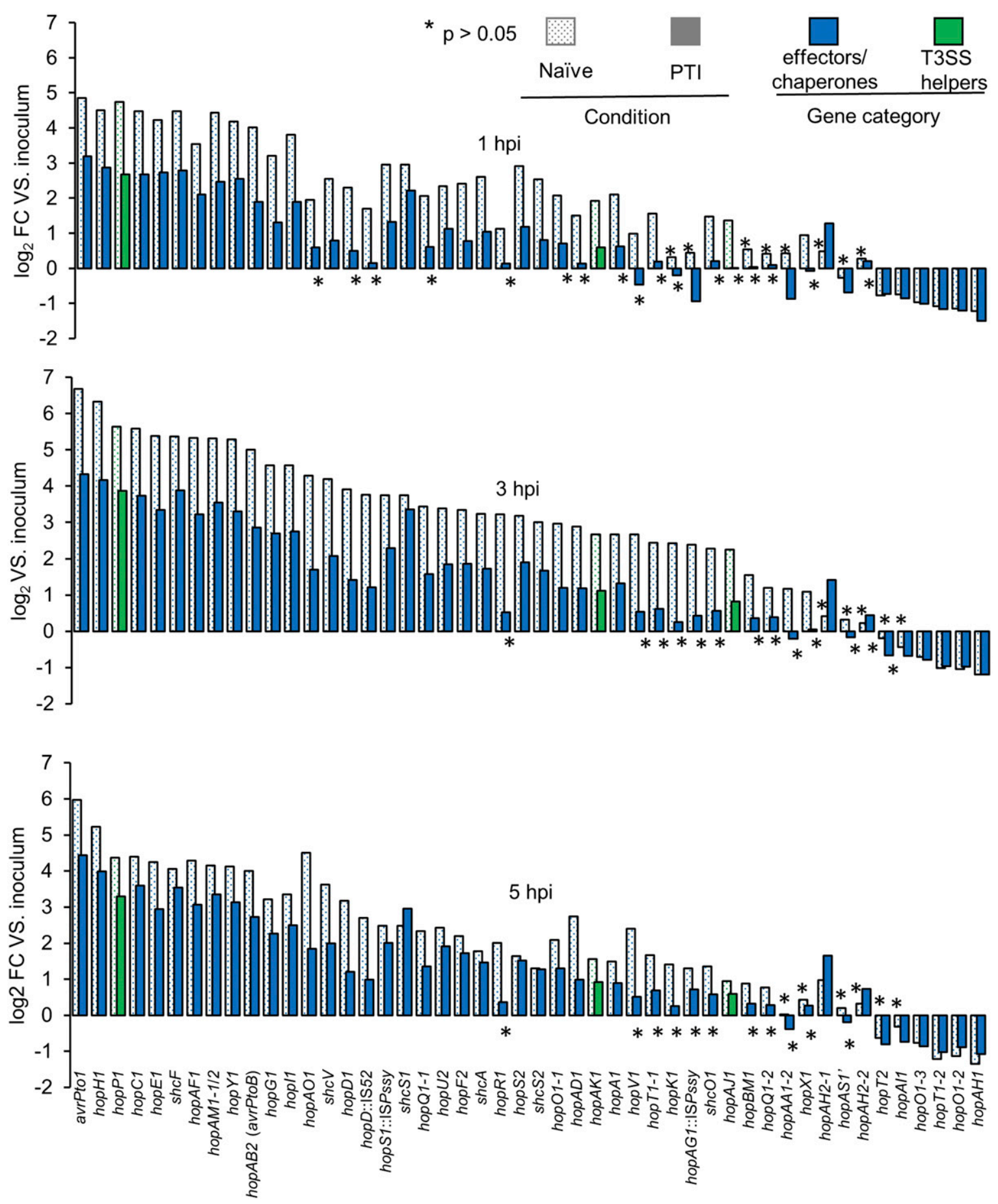

Fig. 6. Upregulation of Pseudomonas syringae pv. tomato DC3000 effector genes relative to the starting inoculum for varying timepoints. Differentially expressed bacterial effector genes found outside the pathogenicity island of $P$. syringae pv. tomato DC3000 in in-planta samples under two conditions (patterntriggered immunity [PTI] and naïve) relative to the starting inoculum (inoculum) measured as $\log _{2}$ fold change in mean normalized gene counts. Differential expression was calculated using the DESeq function in the DESeq2 v.1.14.1 R package. Genes sorted by the naive $3 \mathrm{~h}$ postinoculation (hpi) sample. Asterisks indicate not significantly differentially expressed genes $(P>0.05)$ for naive samples (above $x$ axis) and PTI samples (below $x$ axis). 
infection. The T3SS pilin hrpAl experienced only subtle nonsignificant changes in relative expression values. The statistical correlation between expression trends comparing in-planta expression to the starting inoculum also exhibited a positive correlation ( $r>0.76)$ when measured using both RT-qPCR and RNASeq (Supplementary Fig. S5). However, for some genes, there was less agreement in the directionality of the relative expression trends as measured using the two methods. For example, during PTI exposure, $c f l$, as measured by RT-qPCR, was observed to have decreased relative expression during PTI exposure relative to the starting inoculum at all timepoints; however, as measured by RNASeq, relative expression of $c f l$ during PTI exposure was observed to be higher, relative to the starting inoculum, by 3 hpi (Fig. 9).

\section{DISCUSSION}

Time course transcriptomics analysis of pathogens in situ can provide a global view of transcriptional regulation and dynamics during plant-microbe interactions. However, studying these interactions during early timepoints can be challenging due, in part, to the large imbalance between plant cytosolic and
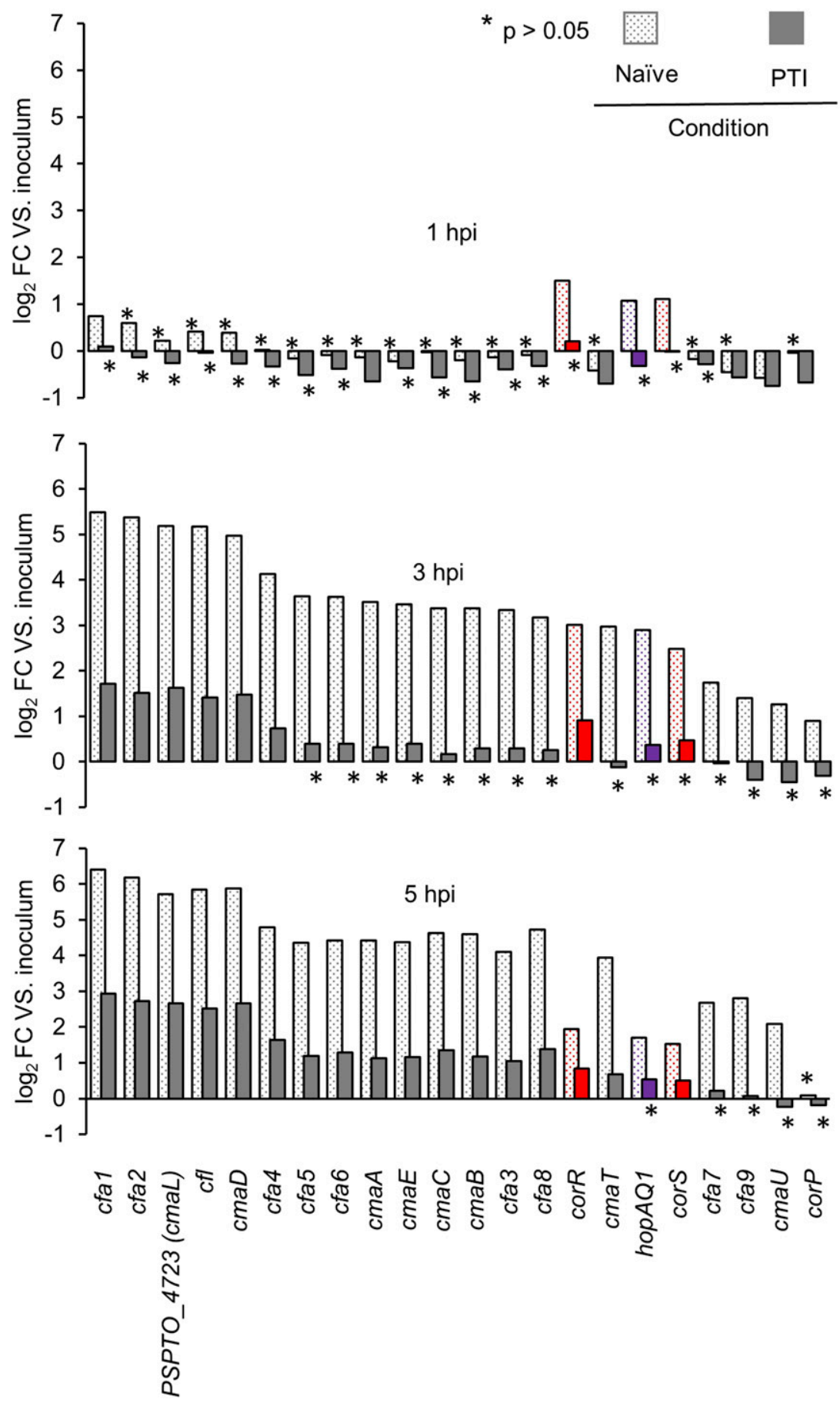

Fig. 7. Upregulation of Pseudomonas syringae pv. tomato DC3000 coronatine biosynthesis genes relative to the starting inoculum by $3 \mathrm{~h}$ postinoculation (hpi). Differentially expressed bacterial coronatine biosynthesis genes of $P$. syringae pv. tomato DC3000 in in-planta samples under two conditions (pattern-triggered immunity [PTI] and naive) relative to the starting inoculum (inoculum) measured as $\log _{2}$ fold change in mean normalized gene counts. Differential expression was calculated using the DESeq function in the DESeq2 v.1.14.1 R package. Genes sorted by naive 3-hpi sample. Asterisks indicate not significantly differentially expressed genes $(P>0.05)$ for naïve samples (above $x$ axis) and PTI samples (below $x$ axis). 
organellar RNA and bacterial RNA. Here, we use a method based on physical separation of RNA-stabilized bacteria from leaf tissue using low-speed centrifugation followed by bacterial ribosome depletion to enrich the total RNA pool for bacterial mRNA. Using this method, between 10 and $46 \%$ of sequencing reads mapped to the DC3000 reference genome, with our lowest read depth being 6.4 million reads mapped. This is well above the accepted threshold for effective bacterial transcriptomics analysis (Haas et al. 2012). We recognize that the "spin out" method has its limitations in that high doses of bacteria were utilized to isolate sufficient bacterial RNA for downstream analysis. It is possible that these high bacterial loads may skew interpretations of density-dependent gene regulation or may alter the apoplastic environment in some nonphysiologically relevant manner. It is also possible that the population of bacteria extracted and analyzed using our method may not be representative of the population on the whole within inoculated leaves. To address these concerns, we used RTqPCR to analyze RNA recovered from whole inoculated leaves using a more typical bacterial dose. The high positive correlation between relative expression values of key pathway genes under in-planta treatments as measured by RT-qPCR and RNAseq supports the interpretation that our observations are neither artifacts of high bacterial dose nor our method of bacterial RNA enrichment (Fig. 9). Although the correlation was weaker when comparing relative expression between starting inoculum and in-planta samples, the general expression trends were supported by high positive correlation, as defined by Mukaka (2012), as having a Pearson's correlation coefficient greater than 0.7 . Weaker correlation when comparing relative expression to starting inoculum could be explained by greater variability in transcriptome profiles in inoculum samples compared with in-planta samples (Fig. 3). Given the strong correlation between our RNASeq and RT-qPCR relative expression, the bacteria extracted for RNASeq analysis is likely representative of the dominant population within the infected tissue, as whole infected leaf tissue was analyzed by RT-qPCR. We recognize that the concentration of bacteria used in the RT-qPCR analysis is higher than what would be observed in a natural setting and only a subset of genes was tested for correlation and the high positive correlation may not be observed for genes outside of our analysis.

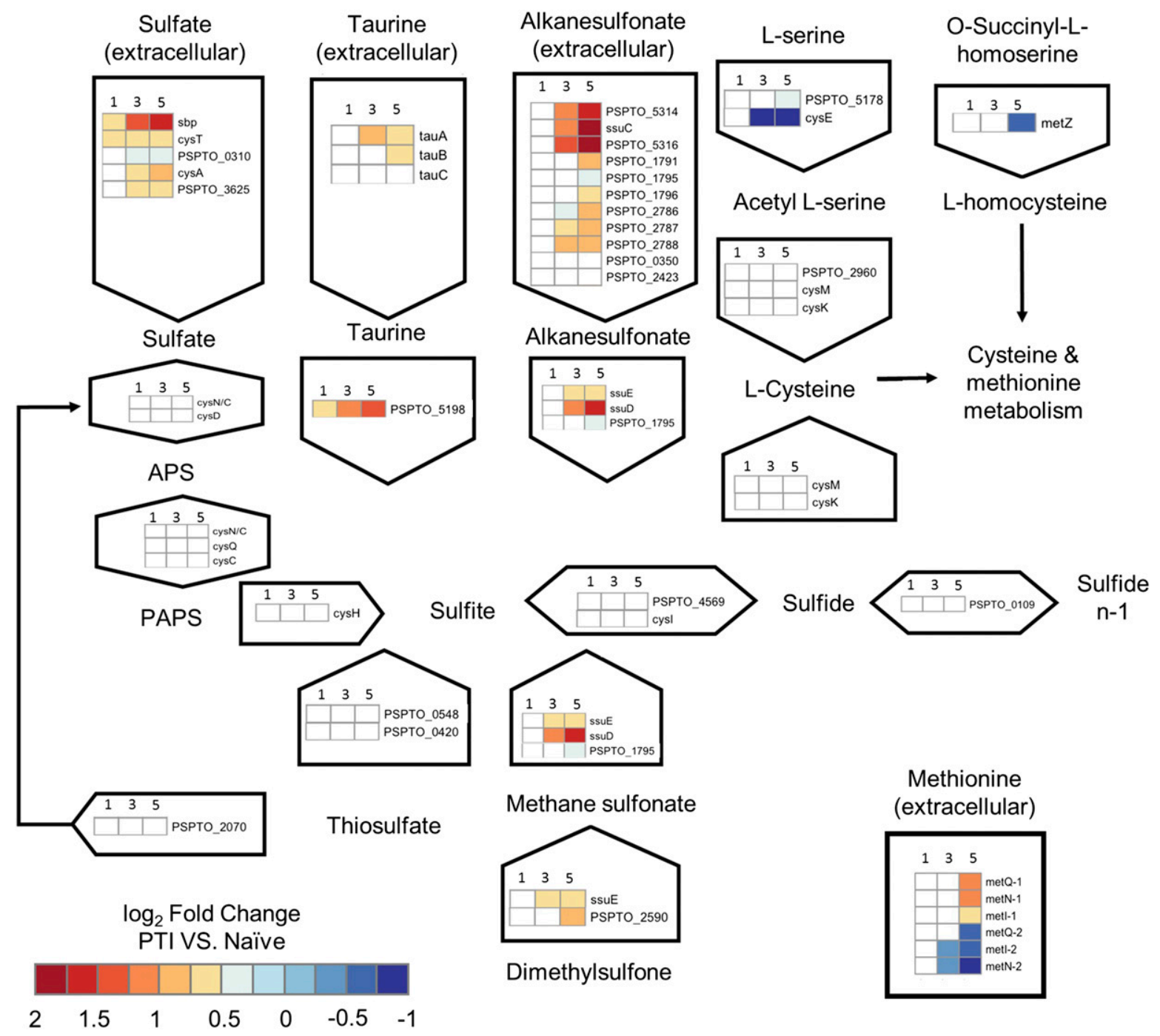

Fig. 8. Upregulation of Pseudomonas syringae pv. tomato DC3000 sulfur starvation response genes in bacteria exposed to pattern-triggered immunity (PTI). Heat map of $\log _{2}$ fold change in mean normalized counts for P. syringae pv. tomato DC3000 sulfur metabolism genes in a KEGG (Kyoto Encyclopedia of Genes and Genomes) pathway gene set for bacteria exposed to PTI-induced (PTI) Arabidopsis thaliana leaves relative to bacteria during naïve infection (naïve) of $A$. thaliana leaves at 1,3 , and $5 \mathrm{~h}$ postinoculation. Components of the sulfur metabolism pathway were taken from KEGG. Differential expression was calculated using the DESeq function in the DESeq2 v.1.14.1 R package. White cells are not significantly differentially expressed (padj $>0.05$ ). Blue and red cells are significantly differentially downregulated and upregulated, respectively $($ padj $<0.05)$. 
We used the spin out protocol to analyze the time-course transcriptional responses of DC3000 to PTI induced and naïve A. thaliana leaf tissue at early timepoints following infection. Principal components analysis comparing the transcriptomes of the starting inoculum with bacteria exposed to PTI for 1,3 , and 5 hpi or bacteria during naïve host infection for 1,3 , and 5 hpi showed a similar, initially rapid, transcriptional profile switch during naïve host infection and exposure to PTI as bacteria adapted to the apoplast at $1 \mathrm{hpi}$. During naïve host infection, there was an additional shift in the bacterial transcriptome profile at $3 \mathrm{hpi}$, indicating an infection-associated shift in transcriptional regulation. In contrast, for bacteria exposed to PTI, there was no transition in the transcriptome profile beyond the initial adaptation to in-planta conditions, possibly indicating that the bacteria were unable to manipulate the host niche.
A

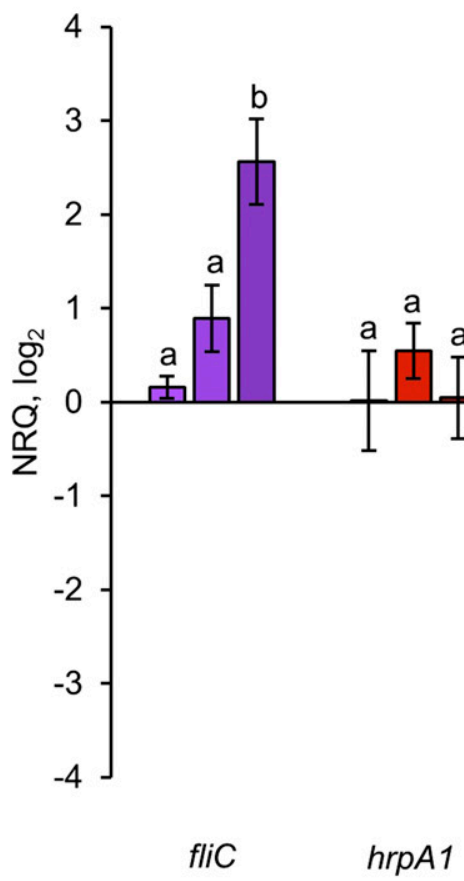

Condition Gene

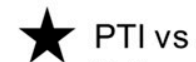
Naïve

hrpA1

PSPTO_5316

sbp

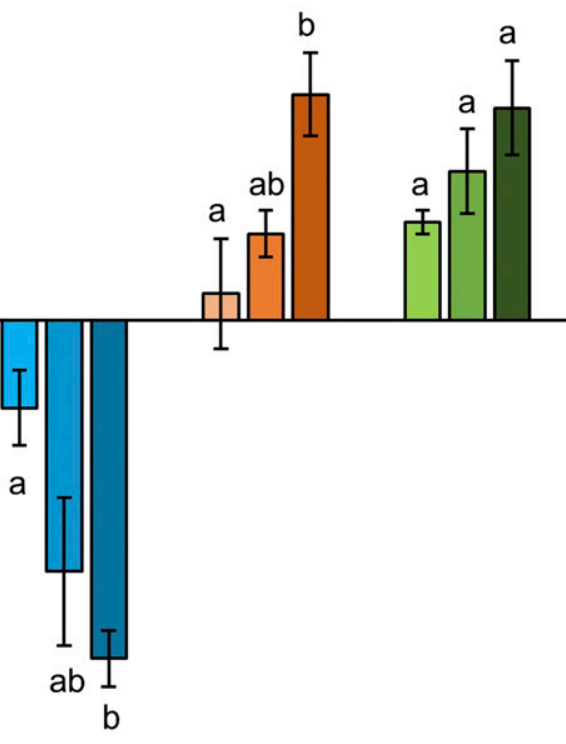

cfl

1

3

5

$s b p$

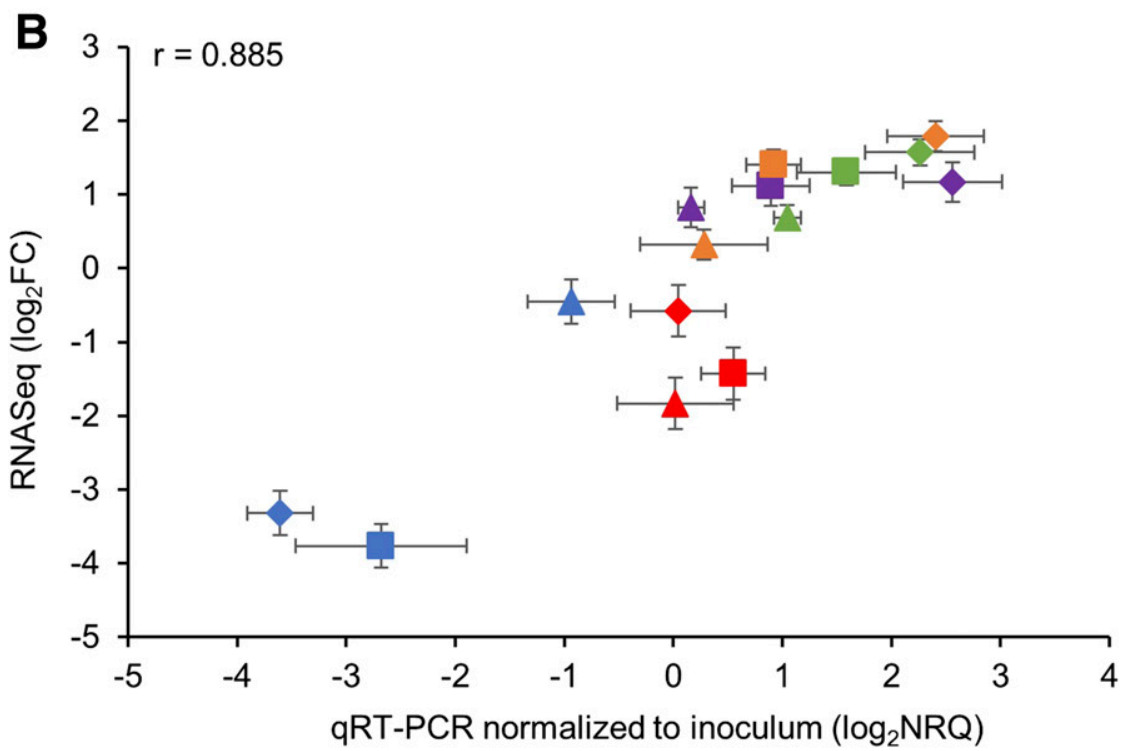

Condition Gene

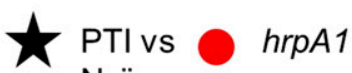

Naïve

PSPTO 5316

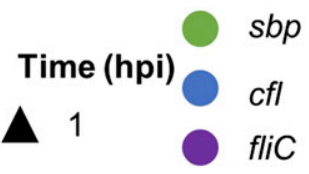

3

5

Fig. 9. Reverse transcription-quantitative polymerase chain reaction (RT-qPCR) analysis of Pseudomonas syringae pv. tomato DC3000 gene expression during early exposure to pattern-triggered immunity (PTI) relative to naive host infection of Arabidopsis thaliana. A, Expression of five genes of interest ( $h r p A 1$, PSPTO_5316, sbp, $c f l$, and $f l i C$ ) in bacteria exposed to PTI relative to expression in bacteria during naïve host infection (PTI versus naïv), normalized against the expression of two reference genes, $r e c A$ and $o p r F$. Bars represent mean $\log _{2}$ normalized relative quantity (NRQ) and standard error calculated from independent biological replicate samples $(n=3)$. Different letters indicate statistically significant difference between times for each gene of interest based on one-way analysis of variance with Tukey's honest significance test (padj < 0.05). B, Correlation of relative expression of five genes of interest in bacteria exposed to PTI relative to expression in bacteria during naïve host infection (PTI versus naïve) measured by qRT-PCR as the log 2 NRQ ( $x$ axis) and RNASeq as the $\log _{2}$ fold change (FC). Points represent mean relative expression and standard error calculated from independent biological replicate samples $(n=3)$. Pearson's correlation coefficient, $r$, calculated from all points. 
Pathway analysis revealed a significant downregulation in growth-associated pathways in bacteria exposed to PTI relative to bacteria during naive host infection. This suggests that bacteria enter a stationary phase-like state upon exposure to PTI and are unable to replicate. This is further supported by the observed significant lack in growth of bacteria from PTI-induced leaf tissue at 5 and $12 \mathrm{hpi}$, compared with bacteria during naïve host infection. PTI pre-induction in plants has been previously shown to protect against bacterial infection (Zipfel et al. 2004); however, this phenotype was captured within days after infection. Our data show that, during exposure to PTI, the number of recoverable bacteria can be significantly reduced by as early as $5 \mathrm{hpi}$.

Recent studies showed that PTI restricts the capacity of $P$. syringae to translocate T3Es into plant cells (Anderson et al. 2014; Crabill et al. 2010; Oh et al. 2010; Wei et al. 2013). The T3SS is a critical virulence factor for many pathogenic bacteria. In $P$. syringae, the T3SS and T3Es are regulated by the ECF sigma factor HrpL, which allows recognition and transcription from consensus "hrp box" promoters (Frederick et al. 2001). $\mathrm{HrpL}$ is induced under $h r p$-inducing conditions and is regulated by the RpoN enhancers HrpR and HrpS (Lan et al. 2006). We found that HrpL-regulated genes were differentially induced in planta, compared with the starting inoculum, by $1 \mathrm{hpi}$, with peak relative expression at $3 \mathrm{hpi}$. This result was consistent with the rapid expression of the T3E gene avrPtol, which was found to be induced in infecting DC3000 at $1 \mathrm{hpi}$ in tomato (Salmeron and Staskawicz 1993). In bacteria exposed to PTI, the T3SSassociated genes were induced up to sixfold less than bacteria during naïve host infection. PTI-associated reduction in T3SS expression was also observed by Anderson et al. (2014) in Arabidopsis mpkl mutants with overactive PTI. In general, hrpR and $h r p S$ showed similar expression patterns during naïve host infection and exposure to PTI. Conversely, $h r p L$ displayed similar differential expression with bacteria exposed to PTI and during naïve host infection as with other HrpL-regulated genes. This likely indicates that the decreased induction of HrpL-regulon genes is primarily due to the decreased induction of $h r p L$ and that PTI interference in $h r p L$ induction occurs downstream of HrpR and HrpS.

During naïe host infection, peak relative expression of $h r p L$ and $h r p L$-regulated genes was observed at $3 \mathrm{hpi}$, which was followed by a decrease in expression at 5 hpi. However, bacteria exposed to PTI had more stable induction of T3SS-associated genes at all timepoints. Thus, at $5 \mathrm{hpi}$, the $h r p L$ expressed at a similar level during naive host infection and exposure to PTI. One interpretation for this is that, during naïve host infection, DC3000 perceives a signal to downregulate the transcription of T3SSassociated genes, possibly linked to the increase in bacterial population. However, during exposure to PTI, this signal is absent or not perceived. Another possibility is that the hypothetical hrpL downregulation signal is, in fact, present and perceived by DC3000 from the very beginning of PTI exposure, which could explain the lack of full hrpL induction in bacteria exposed to PTI.

DC3000 delivers at least 30 T3Es that are known to be HrpLregulated and to be translocated into plant cells. (Cunnac et al. 2009; Lam et al. 2014). All these effectors were observed to be induced during infection at some timepoint, confirming the current tally of 30 T3Es. The relative expression of the 30 effectors varied over a 45-fold range, and a subset of effectors were observed to be induced only at certain timepoints during naive host infection. This variation in expression level and timing is evidence for a hierarchy of T3Es during naive host infection. During exposure to PTI, a subset of effectors was either not differentially expressed or delayed in expression. For most of these effectors, this could be attributed to lower induction by HrpL sigma factor, as they are paired with lower expression during naive host infection.
In addition to T3E virulence factors, DC3000 produces coronatine, a chlorosis-inducing phytotoxin that plays a role in pathogenicity by manipulating host jasmonate signaling (Greulichi et al. 1995; Palmer and Bender 1995). By manipulating hormone signaling in the host, coronatine can overcome PTI-driven stomatal defense by reopening closed stomata, thus facilitating bacterial invasion (Zeng and He 2010; Zeng et al. 2011). Coronatine biosynthesis genes are encoded by the $c f a$ and $c m a$ operons and are regulated by a two-component system comprised of the histidine kinase CorS and the response regulator CorR (Rangaswamy and Bender 2000). A confirmed hrp box is present upstream of corR and the HrpL-regulated gene hopAQ1. Thus, in DC3000, the HrpL sigma factor plays a role in regulation of coronatine biosynthesis through corR expression (Sreedharan et al. 2006). In our study, coronatine regulators corR and corS as well as the HrpLregulated gene hopAQ1 were the first coronatine-associated genes to be differentially expressed in bacteria during naïve host infection, at 1 hpi with peak relative expression by 3 hpi. In contrast, the coronatine biosynthesis genes $c f a$ and $c m a$ had peak relative expression at $5 \mathrm{hpi}$. Our observations support the regulatory role the two-component system and sigma factor HrpL play in coronatine biosynthesis. During exposure to PTI, coronatine biosynthesis genes had consistently less relative expression than during naive host infection, with regulator genes exhibiting peak observed expression at 5 hpi. This phenotype is similar to that found in the T3SS, indicating that misregulation of coronatine biosynthesis regulation during exposure to PTI could be attributed to $h r p L$ misregulation, since corR expression is HrpL-dependent. However, the lack in repression of coronatine biosynthesis by 5 hpi suggests that PTI exposure interference with corR expression may not be solely dependent on $h r p L$.

In DC3000 the sigma factor AlgU also regulates multiple virulence factors, including the induction of alginate synthesis and the T3SS-associated genes through the induction of $h r p R$, and the repression of flagellar genes (Markel et al. 2016; Schreiber and Desveaux 2011). Alginate biosynthesis in pseudomonads has been shown to play an important role in mediating osmotic and oxidative stress and has been proposed to function in the protection against plant host innate immunity (Aslam et al. 2008). The comparison of differentially expressed pathways between bacterial starting inoculum and in-planta bacterial samples revealed a significant downregulation in motility pathways, with significant repression of the flagellar system in bacteria extracted from in-planta samples. It was previously established that $P$. syringae suppresses presentation of the flagellin during infection, possibly to reduce detection by FLS2 (Clarke et al. 2013; Pel et al. 2014; Schreiber and Desveaux 2011; Takeuchi et al. 2003). Our data support previous observations of downregulation of $P$. syringae flagellar expression on T3SS-inducing media (Schreiber and Desveaux 2011). We demonstrated that bacteria exposed to PTI exhibited a significantly higher relative expression in motility pathways, oxidative stress, and osmotic stress response genes, and significant downregulation in alginate biosynthesis genes, relative to bacteria during naïve host infection. PTI exposure appears to reduce $\mathrm{AlgU}$-associated transcriptional regulation in planta; however, the mechanism by which PTI exposure interferes with AlgU-driven regulation remains an open question.

Pathway analysis revealed a significant increase in sulfur metabolism genes that was uniquely specific to bacteria exposed to PTI. Of the DC3000 genes annotated for the sulfur metabolism pathway in the KEGG database, most of the DEGs were ABC transporters for sulfate, sulfonates and taurine, and methionine. The upregulation of these importer genes correlates with sulfate starvation-induced proteins previously found to be produced by Pseudomonas aeruginosa under sulfate-limiting conditions (Kertesz 2000). Sulfur is a limiting essential nutrient for the 
synthesis of the sulfur-containing amino acids cysteine and methionine as well as iron-sulfur cluster cofactors. Therefore, a sulfur-limiting environment within the apoplast during PTI could restrict the growth of apoplastic bacteria. Transcriptional analysis of A. thaliana during PTI and infection showed differential expression of sulfate transporter genes located in the leaves, demonstrating the importance of sulfate movement during plantmicrobe interactions (Lewis et al. 2015; Thilmony et al. 2006). The tomato sulfate transporter 2 gene was induced by flagella but repressed by effectors during infection by DC3000, indicating that sulfur limitation during PTI is not unique to Arabidiopsis (Rosli et al. 2013). In addition, virulence effectors from $P$. syringae and oomycete pathogens have been shown to bind with A. thaliana response to low-sulfur proteins (Mukhtar et al. 2011), and Xanthomonas oryzae pv. oryzicola TAL effectors were verified to bind to sulfate transporter gene promoters in rice (Cernadas et al. 2014). T3E-driven regulation of sulfate importers in multiple plant-pathogen systems supports the model that pathogen effectors may act to counter PTI-dependent sulfate sequestration. Our findings, along with published results, support the hypothesis that sulfur limitation could be a potential mechanism for bacterial restriction during PTI.

It is also possible that the sulfur starvation response observed in DC3000 is linked to the PTI-associated oxidative burst (O'Brien et al. 2012). Iron-sulfur cluster cofactors involved in important physiological processes are notably sensitive to damage by reactive oxygen and exposure to oxidative stress has been observed to be associated with the induction of bacterial sulfur assimilation genes (Fuangthong et al. 2015; Riboldi et al. 2014). However, conversely, direct sulfate limitation in $P$. aeruginosa was also observed to be associated with the significant upregulation of oxidative stress response genes including katB and ahpC (Tralau et al. 2007). Our future studies will aim to deconvolute the transcriptional and mechanistic interactions between sulfur limitation and oxidative stress during PTI exposure.

Previous bacterial transcriptome analyses during host infection has captured the behavior of bacteria at single points in time (Chatnaparat et al. 2016; Yu et al. 2013). The time-course transcriptome analysis of bacteria during early infection and exposure to PTI sheds new light on the dynamic transcriptional changes that occur during the early events of plant-microbe interactions. Interpretation of our own data set would be quite different if only a single timepoint were analyzed. For instance, at $5 \mathrm{hpi}$, differences in $h r p$ regulon expression during PTI exposure and naive host infection were minimal. This study established that early exposure to PTI alters the expression of multiple virulence and motility pathways in $P$. syringae pv. tomato DC3000. We predict that these changes are due to a PTIdriven misregulation of these regulons through interference with key transcriptional regulators. However, the mechanisms by which PTI interferes with virulence regulation and whether this response is a direct or indirect output during PTI is yet to be determined. PTI-associated upregulation of bacterial sulfur metabolism genes may indicate that PTI-associated responses is the sequestration of apoplastic sulfur sources, which could play a role in the restriction of bacterial replication. Future work will aim to clarify whether these PTI outputs are distinct or unified in an ongoing effort to uncover the underlying mechanisms of bacterial restriction during PTI.

\section{MATERIALS AND METHODS}

\section{Plant tissue preparation}

and bacterial infection procedure.

Arabidopsis thaliana seeds (Col-0) were suspended in sterile $0.1 \%$ agarose and were sown four per 3.5-in square pot, using SunGrow Professional growing potting mix and covered in window mesh. Sown pots were stratified for 1 day at $4{ }^{\circ} \mathrm{C}$ in darkness. Col-0 A. thaliana plants were grown in a growth chamber (Conviron A1000) for 4.5 weeks under long-day conditions at $23^{\circ} \mathrm{C}$ (14-h day and 10 -h night) at $70 \mu \mathrm{mol}$ light settings. Two days prior to inoculation, plants were removed from the growth chamber and were placed in a growth room under 12-h day and 12-h night conditions. Individual pots were randomized prior to pretreatment. Four expanded leaves on each plant were marked on each plant.

Four marked leaves, each, on plants ( 24 to 31 per timepoint per treatment) were treated either with $1 \mu \mathrm{M}$ flg22 in $0.1 \%$ DMSO or with $0.1 \%$ DMSO by infiltration with a $1-\mathrm{ml}$ blunt syringe on the abaxial surface. Plants were kept uncovered in the growth room for $20 \mathrm{~h}$ prior to bacterial inoculation.

Pseudomonas syringae pv. tomato DC3000 was streaked from a single colony onto King's B (King et al. 1954) agar plates supplemented with $20 \mu \mathrm{g}$ of rifampicin per milliliter and were grown overnight at room temperature. Bacterial inoculum was smeared into a lawn with $0.2 \mathrm{ml}$ of liquid media $(10 \mathrm{~g}$ Bacto tryptone, $6 \mathrm{~g}$ of Bacto yeast extract, $2 \mathrm{~g}$ of $\mathrm{K}_{2} \mathrm{HPO}_{4} \cdot 3 \mathrm{H}_{2} \mathrm{O}, 0.6 \mathrm{~g}$ of $\mathrm{NaCl}, 0.4 \mathrm{~g}$ of $\mathrm{MgSO}_{4} \cdot 7 \mathrm{H}_{2} \mathrm{O}, 18 \mathrm{~g}$ of agar per liter) and was incubated overnight at room temperature. For individual inoculations, bacteria were harvested from plates, were suspended in $0.25 \mathrm{mM} \mathrm{MgCl}_{2}$, and were diluted to an optical density at $600 \mathrm{~nm}$ of 0.8 (aproximately $1 \times 10^{9} \mathrm{CFU} / \mathrm{ml}$ ), as determined using a Biospectrometer (Eppendorf, Hamburg, Germany). Bacterial suspensions were syringe-infiltrated into pretreated leaves, as described above, through holes poked with a needle in each side of the leaf. Plants were allowed to dry at ambient temperature and humidity for 1,3 , or $5 \mathrm{~h}$ before bacteria were extracted from tissue. A subset of plants $(n=47$ for flg22pretreated leaf tissue and $n=48$ for DMSO-pretreated leaf tissue) were kept at ambient temperature and humidity for $24 \mathrm{~h}$, to allow documentation of symptom development by photography. Inoculation of $A$. thaliana leaf tissue for the bacterial population growth assay was performed on both flg22- and DMSO-pretreated plants inoculated in the same manner described above. Bacterial quantification was determined at $0(n=8), 5(n=12)$, and $12 \mathrm{hpi}$ $(n=8)$, as described (Liu et al. 2015).

\section{Extraction of bacteria from infected plants.}

At 1, 3, and 5 hpi, leaves from each treatment were harvested by cutting at the petiole or leaf blade junction. Leaves were arranged on two sheets of parafilm, were rolled, and were inserted into the barrel of two 20-ml syringes. An RNA stabilizing buffer (De Wit et al. 2012), pH 5.2, was poured into each syringe, which was sealed and vacuum infiltrated at $95 \mathrm{kPa}$ for $2 \mathrm{~min}$, followed by a slow release of the vacuum. Vacuuminfiltration with RNA-stabilizing buffer was conducted twice on inoculated leaves. Excess RNA-stabilizing buffer was decanted and the syringes were placed into $50-\mathrm{ml}$ conical tubes and were centrifuged at $1,000 \times g$ for $10 \mathrm{~min}$ at $4^{\circ} \mathrm{C}$ to recover the intercellular wash fluid (O'Leary et al. 2014). The flow-through was pooled for each treatment and was concentrated by syringe filtration, using a $0.20-\mu \mathrm{m}$ Micropore Express Plus membrane placed within a removable filtering syringe tip adapter (Millipore, Billerica, MA, U.S.A.). Filters were placed in homogenization tubes, were flash frozen in liquid nitrogen, and were stored at $-80^{\circ} \mathrm{C}$ for RNA extraction. This process was conducted three times for each timepoint.

Bacterial RNA extraction, quantification, and sequencing.

The filter membranes were homogenized in Trizol reagent (Thermo Fisher Scientific, Waltham, , MA, U.S.A.) for $1 \mathrm{~min}$ at $1,750 \mathrm{~Hz}$, using a GenoGrinder (SPEX SamplePrep, Metuchen, NJ, U.S.A.) followed by the Direct-Zol Miniprep Plus kits (Zymo Research, Irvine, CA, U.S.A.), which included an on-column 
DNAse I treatment (30 U per column for $15 \mathrm{~min}$ ). RNA samples were additionally treated with TURBO DNase (Invitrogen, Carlsbad, CA, U.S.A.) to eliminate DNA contamination. RNA was quantified using the Biospectrometer and $\mu$ Cuvette G1.0 (Eppendorf). For an inoculum control, $1 \mathrm{ml}$ of the $1 \times 10^{9}-\mathrm{CFU} / \mathrm{ml}$ bacterial inoculum in $0.25 \mathrm{mM} \mathrm{MgCl}$ was pelleted and RNA was extracted as described above. Three independent bacterial suspensions started from three colonies were sampled for a total of three biological replicates.

Gram-negative bacterial rRNA was depleted from total RNA samples, using a Ribo-Zero rRNA removal kit (Illumina, San Diego, CA, U.S.A.) according to manufacturer's instructions, and was confirmed using the Agilent 2100 Bioanalyzer (Agilent Technologies, Waldbronn, Germany). Stranded libraries were constructed using Illumina-compatible TruSeq stranded total RNA library type (Kapa Biosystems, Wilmington, DE, U.S.A.). Samples from a single complete experimental replicate were pooled onto a single flow cell, based on bacterial RNA quantification estimates, with RT-qPCR for a total of three flow cells. Single-end 75-nt reads were sequenced using the Next-seq platform in high-output mode. Bacterial RNA was quantified from DMSO treated 1, 3, and 5 hpi and starting inoculum total RNA samples using RT-qPCR and the $P$. syringae-specific $16 \mathrm{~S}$ rRNA primers found in Table 2 .

\section{RNA-Seq data analysis.}

Reads were quality trimmed using Trimmomatic version 0.32 and were aligned to the RefSeq $P$. syringae pv. tomato DC3000 genome (NC_004278.1, NC_004632.1, NC_004633.1), using EDGE-pro version 1.3.1. Counts of RNA-Seq fragments were computed for each annotated gene, from reads per kilobase million values, using the egdeToDeseq.perl script within EDGE-pro. DEGs were identified from gene counts for each sample, using the Bioconductor package DESeq2 version 3.3.0. DEGs were selected based on $\log _{2}$-transformed and normalized mean counts that have an adjusted $P$ value below a false discovery rate (FDR) cutoff of 0.05 . Principal components analysis of $\log _{2}$-transformed normalized counts was performed for all treatments and replicates, using the rlog function in DESeq2. Hierarchical clustering was performed on $\log _{2}$ fold changes in mean normalized counts between treatments across all timepoints, and heatmaps were generated using the $\mathrm{R}$ package pheatmap version 1.0.8.

Gene set or pathway analysis was conducted using $\log _{2}$ fold change values of normalized mean counts for annotated genes using the Bioconductor package, gauge version 2.24.0. Gene sets of metabolic pathways were obtained, from the KEGG pathway database, using the organismal code "pst" for Pseudomonas syringae pv. tomato DC3000. Significant gene sets were identified from $\log _{2}$ fold changes between treatments at similar timepoints and were selected based on a FDR $q$ value cut-off of 0.05 .

\section{Identification of orthologous genes}

of $P$. syringae pv. syringae $\mathrm{B} 728$ a stress regulons in $\mathrm{DC} 3000$.

Potential osmotic and oxidative stress response genes in DC3000 were identified by finding orthologous genes to the $P$. syringae pv. syringae $\mathrm{B} 728 \mathrm{a}$ genes found in osmotic and oxidative stress regulons by $\mathrm{Yu}$ et al. (2013). Stress response genes in $P$. syringae pv. syringae B728a were searched against the KEGG orthologs sequence similarity database. Orthologous genes were only searched in prokaryotic organisms and the orthologous gene for the organism ID pst (DC3000) was selected only if it was a best hit.

\section{RT-qPCR analysis on select genes of interest.}

Four leaves on nine 4.5-week-old A. thaliana Col-0 plants were treated with $1 \mu \mathrm{M}$ flg 22 and an additional nine plants were treated with $0.1 \%$ DMSO $20 \mathrm{~h}$ prior to inoculation, in the same manner described above. The bacterial inoculum of DC3000 was prepared as described above and was further diluted to a final concentration of approximately $5 \times 10^{7} \mathrm{CFU} / \mathrm{ml}$ and was infiltrated into marked leaves of all plants. At 1, 3, and $5 \mathrm{hpi}$, inoculated leaves from a single plant were harvested, were placed in a homogenizer tube, and were flash-frozen in liquid nitrogen. This was repeated for two additional plants at each timepoint for a total of three biological replicates per treatment and timepoint. Three independent samples of pelleted initial inoculum were also flash-frozen in liquid nitrogen for RTqPCR analysis. RNA extraction, cDNA synthesis, RT-qPCR, and normalization were conducted based on previously described procedures (Smith et al. 2018). Normalized cDNA was tested from seven treatments, i.e., inoculum, bacteria during naive host infection for 1,3 , and $5 \mathrm{hpi}$, and bacteria exposed to PTI for 1, 3, and $5 \mathrm{hpi}$. These samples were tested for relative expression of five genes of interest: coronafacic acid ligase $(c f l)$, flagellin $(f l i C)$, the T3SS pilin protein ( $h r p A l), s b p$, and periplasmic binding protein for a sulfonate $\mathrm{ABC}$ transporter (PSPTO_5316). Samples were grouped by biological replicate set and were tested against five genes of interest, two previously validated reference genes, $\operatorname{rec} A$ and $\operatorname{opr} F$, inoculum, and $P$. syringae-specific $16 \mathrm{~S}$ rRNA within the same plate (Smith et al. 2018). Reference genes selected for our analysis were

Table 2. Reverse transcription-quantitative polymerase chain reaction genes of interest and reference genes and their corresponding sequences for primers

\begin{tabular}{|c|c|c|c|c|}
\hline Gene & Purpose $^{a}$ & Primer name & Primer sequence $5^{\prime}$ to $3^{\prime}$ & Product size (bp) \\
\hline \multirow[t]{2}{*}{ 16S (PSPTO_r01) } & \multirow[t]{2}{*}{ Quantification } & QRT-ps16sV1-F ${ }^{\mathrm{bc}}$ & ACGGGTACTTGTACCTGGTG & \multirow[t]{2}{*}{87} \\
\hline & & QRT-ps16sV1-R ${ }^{b c}$ & CGTTTCCGAGCGTTATCCC & \\
\hline \multirow[t]{2}{*}{ recA (PSPTO_4033) } & \multirow[t]{2}{*}{ RG } & QRT-recA-F ${ }^{b c}$ & TAGAACTTCAGCGCGTTACC & \multirow[t]{2}{*}{101} \\
\hline & & QRT-recA-R ${ }^{b c}$ & GCCAACTGCCTGGTTATCT & \\
\hline \multirow[t]{2}{*}{ oprF (PSPTO_2299) } & \multirow[t]{2}{*}{ RG } & QRT-oprF-F ${ }^{\text {bc }}$ & GGCTTGGCCATTGGTACTAT & \multirow[t]{2}{*}{110} \\
\hline & & QRT-oprF-R ${ }^{\text {bc }}$ & GCGCTGTCGTACATTTCTTTC & \\
\hline \multirow[t]{2}{*}{ cfl (PSPTO_4680) } & \multirow[t]{2}{*}{ GOI } & QRT-cflF (collmer jnw123) & TGCTCGTCTCGTCGCCAAG & \multirow[t]{2}{*}{99} \\
\hline & & QRT-cflR (collmer jnw124) ${ }^{\mathrm{bc}}$ & CGATACCCTTAGTTAGTCCTGTGG & \\
\hline \multirow[t]{2}{*}{ fliC (PSPTO_1949) } & \multirow[t]{2}{*}{ GOI } & QRT-fliC-for ${ }^{\text {bc }}$ & TACCAATCTGAACGGCAAGAA & \multirow[t]{2}{*}{108} \\
\hline & & QRT-fliC-rev ${ }^{\mathrm{bc}}$ & GCGCTCAAAGTCAGAGAGAT & \\
\hline \multirow[t]{2}{*}{ hrpA1 (PSPTO_1381) } & \multirow[t]{2}{*}{ GOI } & QRT-hrpA-for ${ }^{\mathrm{bc}}$ & AAGCCAAGGCCAGTAAAG & \multirow[t]{2}{*}{83} \\
\hline & & QRT-hrpA-rev bc & GGTCTGCTTCTTCATTGTTTC & \\
\hline \multirow[t]{2}{*}{ sbp (PSPTO_0308) } & \multirow[t]{2}{*}{ GOI } & QRT-sbp-for ${ }^{b}$ & ATTAACCAGTCTCACGGCGG & \multirow[t]{2}{*}{104} \\
\hline & & QRT-sbp-rev ${ }^{b}$ & ATTTCGTCAATGTCACCGGC & \\
\hline \multirow[t]{2}{*}{ PSPTO_5316 } & \multirow[t]{2}{*}{ GOI } & QRT-5316-for ${ }^{\mathrm{b}}$ & GTTGCTTGAAGGCCTGAACG & \multirow[t]{2}{*}{104} \\
\hline & & QRT-5316-rev ${ }^{b}$ & ACGCGACGTACAGAAGATCTG & \\
\hline
\end{tabular}

\footnotetext{
${ }^{\mathrm{a}} \mathrm{RG}=$ reference gene; $\mathrm{GOI}=$ gene of interest.

b Primers were designed from the GenBank accessions of Pseudomonas syringae pv. tomato DC3000 (NC_004578.1).

${ }^{c}$ Primers selected from previously published results reported by Smith et al. (2018).
} 
found to be the most stable under in-vitro and in-planta conditions, both during infection and during exposure to PTI up to 24 hpi (Smith et al. 2018). As the conditions upon which these reference genes were validated are similar to those used in our analysis, these reference genes are appropriate to use in our RTqPCR analysis. Primer sequences for genes of interest in RTqPCR analysis are given in Table 2. Relative expression of in-planta samples normalized to the inoculum sample measured as the NRQ of a gene of interest was calculated as described previously (Smith et al. 2018). Relative expression of bacteria exposed to PTI relative to bacteria during naïve host infection measured as the NRQ of a gene of interest was calculated similarly to that above; however, the mean efficiency between the control (naive) and treatment (PTI) samples was utilized in the calculation, since each had different LinRegPCR-derived efficiency values. The mean $\log _{2}$ NRQ values were calculated across all three biological replicates and a two-way analysis of variance (ANOVA) was performed for each gene of interest normalized to the inoculum. A one-way ANOVA was performed on $\log _{2}$ NRQ values for each gene of interest for PTI samples relative to naive samples. ANOVA analysis was conducted using the aov function followed by a Tukey's honest significance test using the TukeyHSD function in RStudio v 1.0.136 (RStudio, Inc., Boston).

\section{ACKNOWLEDGMENTS}

We thank M. Deom, R. Walcott, and L. Yang and D. Baltrus for their helpful discussions and insightful comments during the preparation of this manuscript.

\section{LITERATURE CITED}

Alfano, J. R., and Collmer, A. 1996. Bacterial pathogens in plants: Life up against the wall. Plant Cell 8:1683-1698.

Anderson, J. C., Wan, Y., Kim, Y. M., Pasa-Tolic, L., Metz, T. O., and Peck, S. C. 2014. Decreased abundance of type III secretion system-inducing signals in Arabidopsis mkpl enhances resistance against Pseudomonas syringae. Proc. Natl. Acad. Sci. U.S.A. 111:6846-6851.

Aslam, S. N., Newman, M. A., Erbs, G., Morrissey, K. L., Chinchilla, D., Boller, T., Jensen, T. T., De Castro, C., Ierano, T., Molinaro, A., Jackson, R. W., Knight, M. R., and Cooper, R. M. 2008. Bacterial polysaccharides suppress induced innate immunity by calcium chelation. Curr. Biol. 18: 1078-1083.

Bender, C. L., Palmer, D. A., Peñaloza-Vázquez, A., Rangaswamy, V., and Ullrich, M. 1998. Biosynthesis and regulation of coronatine, a non-hostspecific phytotoxin produced by Pseudomonas syringae. Subcell. Biochem. 29:321-341.

Boch, J., Joardar, V., Gao, L., Robertson, T. L., Lim, M., and Kunkel, B. N. 2002. Identification of Pseudomonas syringae pv. tomato genes induced during infection of Arabidopsis thaliana. Mol. Microbiol. 44: 73-88.

Böhm, H., Albert, I., Fan, L., Reinhard, A., and Nürnberger, T. 2014. Immune receptor complexes at the plant cell surface. Curr. Opin. Plant Biol. 20:47-54.

Boutrot, F., and Zipfel, C. 2017. Function, discovery, and exploitation of plant pattern recognition receptors for broad-spectrum disease resistance. Annu. Rev. Phytopathol. 55:257-286.

Buscaill, P., and Rivas, S. 2014. Transcriptional control of plant defence responses. Curr. Opin. Plant Biol. 20:35-46.

Cernadas, R. A., Doyle, E. L. Niño-Liu, D. O., Wilkins, K. E., Bancroft, T., Wang, L., Schmidt, C. L., Caldo, R., Yang, B., White, F. F., Nettleton, D., Wise, R. P., and Bogdanove, A. J. 2014. Code-assisted discovery of TAL effector targets in bacterial leaf streak of rice reveals contrast with bacterial blight and a novel susceptibility gene. PLoS Pathog. 10: e 1003972 .

Chapelle, E., Alunni, B., Malfatti, P., Solier, L., Pedron, J., Kraeipiel, Y., and Van Gijsegem, F. 2015. A straightforward and reliable method for bacterial in planta transcriptomics: Application to the Dickeya dadantiil Arabidopsis thaliana pathosystem. Plant J. 82:352-362.

Chatnaparat, T., Prathuangwong, S., and Lindow, S. E. 2016. Global pattern of gene expression of Xanthomonas axonopodis pv. glycines within soybean leaves. MPMI 29:508-522.
Chen, L. Q. 2010. Sugar transporters for intercellular exchange and nutrition of pathogens. Nature 468:527-532.

Clarke, C. R., Chinchilla, D., Hind, S. R., Taguchi, F., Miki, R., Ichinose, Y., Martin, G. B., Leman, S., Felix, G., and Vinatzer, B. A. 2013. Allelic variation in two distinct Pseudomonas syringae flagellin epitopes modulates the strength of plant immune responses but not bacterial motility. New Phytol. 200:847-860.

Coll, N. S., Epple, P., and Dangl, J. L. 2011. Programmed cell death in the plant immune system. Cell Death Differ. 18:1247-1256.

Crabill, E., Joe, A., Block, A., van Rooyen, J. M., and Alfano, J. R. 2010. Plant immunity directly or indirectly restricts the injection of type III effectors by the Pseudomonas syringae type III secretion system. Plant Physiol. 154:233-244.

Cunnac, S., Lindeberg, M., and Collmer, A. 2009. Pseudomonas syringae type III secretion system effectors: Repertoires in search of functions. Curr. Opin. Microbiol. 12:53-60.

De Wit, P., Pespeni, M. H., Ladner, J. T., Barshis, D. J., Seneca, F., Jaris, H., Overgaard Therkildsen, N., Morikawa, M., and Palumbi, S. R. 2012. The simple fool's guide to population genomics via RNA-Seq: An introduction to high-throughput sequencing data analysis. Mol. Ecol Resour. 12:1058-1067.

Frederick, R. D., Ahmad, M., Majerczak, D. R., Arroyo-Rodriguez, A. S., Manulis, S., and Coplin, D. L. 2001. Genetic organization of the Pantoed stewartii subsp. stewartii hrp gene cluster and sequence analysis of the $h r p A, h r p C, h r p N$, and wtsE operons. Mol. Plant-Microbe Interact. 14: 1213-1222.

Fuangthong, M., Jittawuttipoka, T., Wisitkamol, R., Romsang, A., Duang-nkern, J., Vattanaviboon, P., and Mongkolsuk, S. 2015. IscR plays a role in oxidative stress resistance and pathogenicity of a plant pathogen, Xanthomonas campestris. Microbiol. Res. 170:139-146.

Fukuoka, S., Saka, N., Mizukami, Y., Koga, H., Yamanouchi, U., Yoshioka, Y., Hayashi, N., Ebana, K., Mizobuchi, R., and Yano, M. 2015. Gene pyramiding enhances durable blast disease resistance in rice. Sci. Rep. 5:7773

Glazebrook, J. 2005. Contrasting mechanisms of defense against biotrophic and necrotrophic pathogens. Annu. Rev. Phytopathol. 43:205-227.

Greulichi, F., Yoshihara, T., and Ichihara, A. 1995. Coronatine, a bacterial phytotoxin, acts as a stereospecific analog of jasmonate type signals in tomato cells and potato tubes. J. Plant Physiol. 147:359-366.

Guo, M., Tian, F., Wamboldt, Y., and Alfano, J. R. 2009. The majority of the type III effector inventory of Pseudomonas syringae pv. tomato DC3000 can suppress plant immunity. Mol. Plant-Microbe Interact. 22: 1069-1080.

Haas, B. J., Chin, M., Nusbaum, C., Birren, B. W., and Livny, J. 2012. How deep is deep enough for RNA-Seq profiling of bacterial transcriptomes? BMC Genomics 13:734.

Jin, Q., and He, S. Y. 2001. Role of the Hrp pilus in type III protein secretion in Pseudomonas syringae. Science 294:2556-2558.

Jones, J. D., and Dangl, J. L. 2006. The plant immune system. Nature 444: 323-329.

Kertesz, M. A. 2000. Riding the sulfur cycle-Metabolism of sulfonates and sulfate esters in gram-negative bacteria. FEMS Microbiol. Rev. 24: 135-175.

King, E. O., Ward, M. K., and Raney, D. E. 1954. Two simple media for the demonstration of pyocyanin and fluorescin. J. Lab. Clin. Med. 44: 301-307.

Lam, H. N., Chakravarthy, S., Wei, H. L., BuiNguyen, H.C., Stodghill, P. V., Collmer, A., Swingle, B. M., and Cartinhour, S. W. 2014. Global analysis of the HrpL regulon in the plant pathogen Pseudomonas syringae pv. tomato DC3000 reveals new regulon members with diverse functions. PLoS One 9:e106115.

Lan, L., Deng, X., Zhou, J., and Tang, X. 2006. Genome-wide gene expression analysis of Pseudomonas syringae pv. tomato DC3000 reveals overlapping and distinct pathways regulated by $h r p L$ and $h r p R S$. Mol. Plant-Microbe Interact. 19:976-987.

Lewis, L. A., Polanski, K., de Torres-Zabala, M., Jayaraman, S., Bowden, L., Moore, J., Penfold, C. A., Jenkins, D. J., Hill, C., Baxter, L., Kulasekaran, S., Truman, W., Littlejohn, G., Prusinska, J., Mead, A., Steinbrenner, J., Hickman, R., Rand, D., Wild, D. L., Ott, S., BuchananWollaston, V., Smirnoff, N., Beynon, J., Denby, K., and Grant, M. 2015. Transcriptional dynamics driving MAMP-triggered immunity and pathogen effector-mediated immunosuppression in Arabidopsis leaves following infection with Pseudomonas syringae pv tomato DC3000. Plant Cell 27:3038-3064.

Li, C. M., Brown, I., Mansfield, J., Stevens, C., Boureau, T., Romantschuk, M., and Taira, S. 2002. The Hrp pilus of Pseudomonas syringae elongates from its tip and acts as a conduit for translocation of the effector protein HrpZ. EMBO (Eur. Mol. Biol. Organ.) J. 21:1909-1915. 
Liu, X., Sun, Y., Kørner, C. J., Du, X., Vollmer, M. E., and PajerowskaMukhtar, K. M. 2015. Bacterial leaf infiltration assay for fine characterization of plant defense responses using the Arabidopsis thaliana-Pseudomonas syringae pathosystem. J. Vis. Exp. 104:e53364.

Macho, A. P., and Zipfel, C. 2014. Plant PRRs and the activation of innate immune signaling. Mol. Cell 54:263-272.

Macho, A. P., and Zipfel, C. 2015. Targeting of plant pattern recognition receptor-triggered immunity by bacterial type-III secretion system effectors. Curr. Opin. Microbiol. 23:14-22.

Markel, E., Stodghill, P., Bao, Z., Myers, C. R., and Swingle, B. 2016. AlgU controls expression of virulence genes in Pseudomonas syringae pv. tomato DC3000. J. Bacteriol. 198:2330-2344.

McDowell, J. M., and Woffenden, B. J. 2003. Plant disease resistance genes: Recent insights and potential applications. Trends Biotechnol. 21:178-183.

Melotto, M., Underwood, W., Koczan, J., Nomura, K., and He, S. Y. 2006. Plant stomata function in innate immunity against bacterial invasion. Cell 126:969-980.

Mukaka, M. M. 2012. Statistics corner: A guide to appropriate use of correlation coefficient in medical research. Malawi Med. J. 24:69-71.

Mukhtar, M. S., Carvunis, A. R., Dreze, M., Epple, P., Steinbrenner, J., Moore, J., Tasan, M., Galli, M., Hao, T., Nishimura, M. T., Pevzner, S. J., Donovan, S. E., Ghamsari, L., Santhanam, B., Romero, V., Poulin, M. M., Gebreab, F., Gutierrez, B. J., Tam, S., Monachello, D., Boxem, M., Harbort, C. J., McDonald, N., Gai, L., Chen, H., He, Y. European Union Effectoromics Consortium, Vandenhaute, II, J., Roth, F. P., Hill, D. E., Ecker, J. R., Vidal, M., Beynon, J., Braun, P., and Dangl, J. L.2011. Independently evolved virulence effectors converge onto hubs in a plant immune system network. Science 333:596-601.

O’Brien, J. A., Daudi, A., Butt, V. S., and Bolwell, G. P. 2012. Reactive oxygen species and their role in plant defence and cell wall metabolism. Planta 236:765-779.

O’Leary, B. M., Rico, A., McCraw, S., Fones, H. N., and Preston, G. M. 2014. The infiltration-centrifugation technique for extraction of apoplastic fluid from plant leaves using Phaseolus vulgaris as an example. J. Vis. Exp. 94:e52113.

Oh, H. S., Park, D. H., and Collmer, A. 2010. Components of the Pseudomonas syringae type III secretion system can suppress and may elicit plant innate immunity. Mol. Plant-Microbe Interact. 23:727-739.

Palmer, D. A., and Bender, C. L. 1995. Ultrastructure of tomato leaf tissue treated with the pseudomonad phytotoxin coronatine and comparison with methyl jasmonate. Mol. Plant-Microbe Interact. 8:683-692.

Pel, M. J., van Dijken, A. J., Bardoel, B. W., Seidl, M. F., van der Ent, S., van Strijp, J. A., and Pieterse, C. M. 2014. Pseudomonas syringae evades host immunity by degrading flagelln monomers with alkaline protease AprA. Mol. Plant-Microbe Interact. 27:603-610.

Rangaswamy, V., and Bender, C. L. 2000. Phosphorylation of CorS and CorR, regulatory proteins that modulate production of the phytotoxin coronatine in Pseudomonas syringae. FEMS Microbiol. Lett. 193:13-18.

Riboldi, G. P., Bierhals, C. G., de Mattos, E. P., Frazzon, A. P. G., d'Azevedo, P. A., and Frazzon, J. 2014. Oxidative stress enhances the expression of sulfur assimilation genes: Preliminary insights in the Enterococcus faecalis iron-sulfur cluster machinery regulation. Mem. Inst. Oswaldo Cruz 109:408-413.

Rosli, H. G., Zheng, Y., Pombo, M. A., Zhong, S., Bombarely, A., Fei, Z., Collmer, A., and Martin, G. B. 2013. Transcriptomics-based screen for genes induced by flagellin and repressed by pathogen effectors identifies a cell wall-associated kinase involved in plant immunity. Genome Biol. 14:R139.
Salmeron, J. M., and Staskawicz, B. J. 1993. Molecular characterization and hrp dependence of the avriulence gene avrPro from Pseudomonas syringae pv. tomato. Mol. Gen. Genet. 239:6-16.

Schreiber, K. J., and Desveaux, D. 2011. AlgW regulates multiple Pseudomonas syringae virulence strategies. Mol. Microbiol. 80:364377.

Smith, A., Lovelace, A. H., and Kvitko, B. H. 2018. Validation of RT-qPCR approaches to monitor Pseudomonas syringae gene expression during infection and exposure to pattern-triggered immunity. Mol. Plant-Microbe Interact. 31:410-419.

Sreedharan, A., Penaloza-Vazquez, A., Kunkel, B. N., and Bender, C. L. 2006. CorR regulates multiple components of virulence in Pseudomonas syringae pv. tomato DC3000. Mol. Plant-Microbe Interact. 19:768-779.

Takeuchi, K., Taguchi, F., Inagaki, Y., Toyoda, K., Shiraishi, T., and Ichinose, Y. 2003. Flagellin glycosylation island in Pseudomonas syringae pv. glycinea and its role in host specificity. J. Bacteriol. 185: 6658-6665.

Thilmony, R., Underwood, W., and He, S. Y. 2006. Genome-wide transcriptional analysis of the Arabidopsis thaliana interaction with the plant pathogen Pseudomonas syringae pv. tomato DC3000 and the human pathogen Escherichia coli O157:H7. Plant J. 46:34-53.

Tralau, T., Vuilleumier, S., Thibault, C., Campbell, B. J., Hart, C. A., and Kertesz, M. A. 2007. Transcriptomic analysis of the sulfate starvation response of Pseudomonas aeruginosa. J. Bacteriol. 189:6743-6750.

van der Hoorn, R. A., and Kamoun, S. 2008. From guard to decoy: A new model for perception of plant pathogen effectors. Plant Cell 20: 2009-2017.

Wei, H. L., Chakravarthy, S., Worley, J. N., and Collmer, A. 2013. Consequences of flagellin export through the type III secretion system of Pseudomonas syringae reveal a major difference in the innate immune systems of mammals and the model plant Nicotiana benthamiana. Cell Microbiol. 15:601-618.

Xin, X. F., and He, S. Y. 2013. Pseudomonas syringae pv. tomato DC3000: A model pathogen for probing disease susceptibility and hormone signaling in plants. Annu. Rev. Phytopathol. 51:473-498.

Xin, X. F., Nomura, K., Aung, K., Velasquez, A. C., Yao, J., Boutrot, F., Chang, J. H., Zipfel, C., and He, S. Y. 2016. Bacteria establish an aqueous living space in plants crucial for virulence. Nature 539: 524-529.

Yu, X., Lund, S. P., Scott, R. A., Greenwald, J. W., Records, A. H., Nettleton, D., Lindow, S., Gross, D. C., and Beattie, G. A. 2013. Transcriptional responses of Pseudomonas syringae to growth in epiphytic versus apoplastic leaf sites. PNAS 110:E425-E434.

Zeng, W., Brutus, A., Kremer, J. M., Withers, J. C., and Gao, X. 2011. A genetic screen reveals Arabidopsis stomatal and/or apoplastic defenses against Pseudomonas syringae pv. tomato DC3000. PLoS Pathog. 7: e1002291.

Zeng, W., and He, S. Y. 2010. A prominent role of the flagellin receptor FLAGELLIN-SENSING2 in mediating stomatal response to Pseudomonas syringae pv tomato DC3000 in Arabidopsis. Plant Physiol. 153: 1188-1198.

Zheng, X. Y., Spivey, N. W., Zeng, W., Liu, P. P., Fu, Z. Q., Klessig, D. F., He, S. Y., and Dong, X. 2012. Coronatine promotes Pseudomonas syringae virulence in plants by activating a signaling cascade that inhibits salicylic acid accumulation. Cell Host Microbe 11:587-596.

Zipfel, C., Robatzek, S., Navarro, L., Oakeley, E. J., Jones, J. D. G., Felix, G., and Boller, T. 2004. Bacterial disease resistance in Arabidopsis through flagellin perception. Nature 428:764-767. 